\title{
"Construcción de instrumentos y mecanismos jurídicos locales que garanticen transparencia y rendición de cuentas"4
}

\author{
Adria Velia GONZÁLEZ BELTRONES ${ }^{5}$
}

\begin{abstract}
"La mayoría de las personas entrevistadas en el Barómetro 2010 percibieron un incremento de los niveles de corrupción en sus países durante los últimos tres años. Esto envía un claro mensaje a los líderes de todo el mundo de que el público cree que la corrupción continúa asolando a todas las sociedades. Por ende, es necesario intensificar la búsqueda de mecanismos de transparencia e integridad"
\end{abstract}

Sumario: Introducción. I. Justificación II. Parte conceptual III. Panorama estructural IV. Participación de actores sociales en los Sistemas de Control Gubernamental en Europa y Otros Países V. Estudios de Caso: Propuesta de Rediseño de institución por Nivel de Gobierno en México. VII. Conclusiones

\footnotetext{
${ }^{4}$ Ponencia presentada en el Tercer Congreso Iberoamericano y Cuarto Congreso Mexicano de Derecho Administrativo. "El régimen jurídico del combate a la corrupción.", 24, 25 y 26 de Marzo 2011, IIJ, Facultad de Derecho, Facultad de Estudios Superiores Acatlán, UNAM, México, D.F

${ }^{5}$ Doctora en Ciencias Políticas y Sociales por la UNAM. Investigador de Tiempo Completo, Categoría Titular "C". Pertenece al Grupo de Investigación en Estudios en Ciencias Sociales CIECS. Departamento de Derecho Universidad de Sonora México. http://www.ciiacs.uson.mx E-mail: adriag@sociales.uson.mx.
} 
Introducción

Acorde con el título del presente ensayo, conviene recordar que si bien ha sido científicamente demostrado que uno de los grandes obstáculos para el desarrollo se llama corrupción ${ }^{6} \ldots$ variable, sólida, que explica la miseria arraigada en la mitad de la población del orbe ${ }^{7}$...también es cierto que en el inicio de esta segunda década del Siglo XXI, sabemos apoyados en indagaciones científicas, que la participación social entre otras, es imprescindible para garantizar una mejor sociedad; en este sentido relacionando ambas variables cabe preguntar ¿Cuál es el mejor punto de arranque?,¿cuál la estrategia o estrategias?, ¿ quienes participan? ¿Cuáles son los reglamentos y cuáles los árbitros que intervienen?, ¿en qué tramos?, ¿por cuánto tiempo?, ¿en la carrera o cruzada? ......por abatir la corrupción; y ¿las recompensas, premios, beneficios o logros?, ¿son visibles, medibles, disfrutables?, ¿en cada tramo o hasta el final?, ¿a quiénes corresponde aplicar las bases y reglamentos; vigilar y evaluar que se observe lo que en ellos se establece para compensar el esfuerzo o grado de participación?, ¿ participación, transitoria o permanente? ¿individual, conjunta, mixta o de relevos ?; las respuestas o propuestas de solución a estas interrogantes seguramente se desprenderán de las distintas participaciones de los aquí reunidos en estos dos tradicionales Congresos Iberoamericano y Nacional de Derecho Administrativo, y parte de nuestra responsabilidad será instrumentar su adopción, e implementación, pues la globalización, fenómeno que actualmente permea en todos los ámbitos del quehacer humano, sin duda alguna posibilita que lo que acontece en todo el mundo desarrollado, en el campo de la transparencia, el combate a la corrupción, la rendición de cuentas y la fiscalización, incida en los países en vías de desarrollo y viceversa, por lo que sin más preámbulos paso a

\footnotetext{
${ }^{6}$ La palabra corromper proviene del latín corrumpere y supone alterar la forma de alguna cosa. pero la segunda acepción es más interesante: echar a perder, depravar,dañar, pudrir.

${ }^{7}$ Reyes Heroles Federico, Corrupción: de los ángeles a los índices Cuadernos de transparencia. Num 1 IFAI Sexta edición, México, 2008.pp36
} 
exponer la propia, a la luz de las siguientes precisiones e hipótesis que encuadran nuestra participación sobre el tema rector en el campo de la gestión pública local (Estado de Sonora).

\section{Justificación}

El tema de la corrupción ha sido estudiado ampliamente en el mundo, por instituciones públicas, privadas y por organismos autónomos; su impacto en la sociedad y en su desarrollo es muy notable, por ello la sociedad en su conjunto de los diferentes países reacciona ante ella y, busca mecanismos, instrumentos y factores que permitan disminuirla, atenuarla o frenarla. La opinión pública sobre tal flagelo en nuestro país no se percibe claramente, pues su respuesta -la mayor de las veces- es de pasividad ante los resultados ${ }^{8}$ divulgados y expuestos en medios escritos y en la web por los distintos organismos ${ }^{9}$ enfrascados en el tema,

\footnotetext{
${ }^{8}$ México ocupa junto con Egipto, y Burkina el lugar número 98 de un total de 178 países analizados en la tabla del Índice de Percepción de la Corrupción 2010 de Transparency International. Habiendo obtenido 3.8 de Puntuación del IPC 2010 (La Puntuación del IPC correspondiente a un país o territorio indica el grado de corrupción en el sector público según la percepción de empresarios y analistas de país, entre 10 (percepción de ausencia de corrupción) y 0 (percepción de muy corrupto). ¿Qué tiene más importancia, la clasificación de un país/territorio o su puntuación? La puntuación de un país/territorio $(0$ a 10$)$ indica el nivel de percepción de corrupción del sector público en un país, mientras que la clasificación de un país muestra su ubicación respecto de otros países/territorios incluidos en el índice. Es importante tener presente que la posición que un país ocupa en la clasificación puede variar por el solo hecho de que se hayan incorporado nuevos países al índice o que otros hayan sido excluidos. ¿Pueden las puntuaciones de países/territorios del IPC 2010 compararse con las de índices anteriores? El índice se basa en clasificaciones de países/territorios realizadas a partir de un conjunto variable de encuestas fuente. Por ello, el IPC no es una herramienta adecuada para efectuar comparaciones a lo largo del tiempo. Asimismo, la cantidad de fuentes y países incluidos ha variado desde la creación del IPC en 1995. Algunas fuentes han sido añadidas y otras eliminadas. Con el objeto de mejorar el índice durante los últimos 15 años, TI también ha introducido algunos cambios menores en la metodología. Como consecuencia, el IPC no resulta adecuado para obtener análisis precisos de tendencias.
}

9 Véase Transparency International. Quién se describe así misma en su página web como (a)“Transparencia Internacional (TI), única organización no gubernamental a escala universal dedicada a combatir la corrupción, congrega a la sociedad civil, sector privado y los gobiernos en una vasta coalición global. A través de sus Capítulos en el mundo y su Secretariado Internacional, Transparencia Internacional, aborda las diferentes facetas de la corrupción, tanto al interior de los países como en el plano de las relaciones económicas, comerciales y políticas internacionales. El propósito es comprender y enfrentar los dos rostros de la corrupción: quien corrompe y quien permite ser corrompido. En el ámbito internacional, TI impulsa campañas de concienciación sobre los efectos de la corrupción, promueve la adopción de reformas políticas, el establecimiento de convenciones internacionales sobre la materia; alienta la adhesión a las mismas y luego observa la implementación de dichos acuerdos por parte de los gobiernos, corporaciones y empresas. Asimismo, a nivel nacional, los capítulos de Transparencia Internacional actúan en procura de una mayor transparencia y la materialización del principio de rendición de cuentas. Con este fin, TI monitorea el desempeño de algunas instituciones claves y ejerce presión para la adopción no-partidista de las reformas que sean necesarias. TI no denuncia casos individuales de corrupción (la cual entendemos una tarea fundamental de los periodistas, habiendo muchos de ellos en los capítulos de TI), sino que por el contrario orienta sus esfuerzos en una perspectiva de logros sustentables en el largo plazo, privilegiando la prevención y la reforma de los sistemas.... 
surgidos de las distintas encuestas aplicadas que pretenden medir la percepción de (a)empresarios y analistas o de(b) los hogares en general de cada país, en relación a la corrupción en el ámbito de : partidos políticos, tribunales de impartición de justicia, policía, servicios médicos, sistema educativo, licencias para negocios, cobranza de impuestos, aduanas, servicios de telefonía y comunicaciones, migración, entre otros. De las ediciones para el año 2010 de los "organismos y herramienta precitados", es rescatable para el tema que abordamos lo siguiente: De Transparencia Internacional su señalamiento "Quizás la principal herramienta en la lucha contra la corrupción sea el acceso a la información". Del Barómetro General de la Corrupción la novedad de sondear por primera vez (2010) la disposición del público para comprometerse en la lucha contra la corrupción, el contenido del Apéndice " $C$ ", que permite analizar cómo ha cambiado la percepción de la gente sobre la corrupción y sus experiencias con el pago de sobornos ${ }^{10}$. Comparación de la percepción de corrupción del público en general en el Barómetro 2010 con la percepción de corrupción de los expertos en el Índice de Percepción de la Corrupción $2010^{11}$.En promedio, en los países en que los empresarios, los analistas de país y los expertos perciben que existe corrupción generalizada, también lo percibe el público en general.

Queda entonces precisar lo que las autoridades gubernamentales en México y en especial en el nivel local han realizado al respecto, en la gestión pública, rendición de cuentas en su aplicación y transparencia en su manejo.

\section{Parte conceptual:}

Una trilogía de importancia toral para el combate a la corrupción la constituyen la fiscalización, la transparencia y la rendición de cuentas, con la cual, las

\footnotetext{
${ }^{10}$ Del Cuadro1: se rescata la interrogante ¿Cómo cree que ha evolucionado el nivel de corrupción en este país en los últimos tres años? País/Territorio México, y la alarmante respuesta: 7\% considera que Se redujo, $18 \%$ opina que Se mantuvo igual y $75 \%$ están convencidos que Se incrementó.

${ }^{11}$ (Gráfico 8) La percepción pública y las experiencias de corrupción coinciden con las evaluaciones de los expertos. Dada la naturaleza oculta de la corrupción, los académicos han considerado que las percepciones son un indicador válido de los niveles reales de corrupción. El Barómetro permite examinar esta relación, analizando si las experiencias de las personas con los sobornos administrativos y las percepciones de los expertos que se reflejan en el IPC coinciden. Los resultados demuestran que las experiencias y las percepciones se encuentran estrechamente relacionadas.
} 
administraciones públicas de los países con alto grado de desarrollo o en vías de desarrollo justifican su quehacer ante la sociedad, con el fin de generar dos factores esenciales para la estabilidad y el desarrollo que son la credibilidad y la gobernabilidad.

Los expertos en el tema de la democracia, consideran que debe ser adoptada no solo como un régimen jurídico-político sino como una forma de vida de las naciones y para ello, se debe cimentar en los hechos en sus tres pilares fundamentales que son: el sufragio universal libre y secreto, el estado de derecho y la rendición de cuentas.

1) "Rendición de cuentas" es un término que traduce de manera limitada el significado de la palabra anglosajona accountability, que en inglés significa "el estado de ser sujeto a la obligación de reportar, explicar o justificar algo; [...] ser responsable de algo (liable) [...] ser sujeto y responsable para dar cuentas y responder a preguntas (answerable)"

Accountability se derivan de account, que significa "descripción oral o escrita de eventos o situaciones particulares [...] explicación de una conducta a un superior $[\ldots]$ razones, sustentos [...] balance de ingresos y gastos [...] registros financieros $[\ldots] "$.

En inglés, el sustantivo account derivó en dos términos: accounting, que hace referencia a la profesión de la contabilidad, y accountability, que hace referencia al acto de dar cuentas.

En español, sin embargo, el término "cuenta" (traducción de account) sólo generó el derivado "contabilidad" y nunca desarrolló uno que significara el "acto de dar cuentas". En consecuencia, mientras accounting se ha traducido como contabilidad, accountability carece de un término correspondiente por lo que se le ha traducido como "rendición de cuentas", término de difícil conjugación y que deja 
a la ciencia política y a los políticos hispanoparlantes sin un vocablo adecuado para describir esa característica que es central para las democracias representativas con separación de poderes, como es el caso de México.

b) De la página web ${ }^{12}$ de la Comisión Intersecretarial para la Transparencia y el Combate a la Corrupción, se desprenden los siguientes conceptos

Rendición de Cuentas. Es ese diálogo que debe existir entre autoridades y gobernados, a través de las herramientas idóneas para ello. Un verdadero esquema de rendición de cuentas tiene tres dimensiones básicas: la obligación de los servidores públicos de informar sus decisiones; la obligación de dichos servidores públicos de justificarlas frente a los gobernados, y la posibilidad de la sanción por la violación a sus deberes públicos.

Produce efectos como: los ciudadanos se involucran en las actividades gubernamentales; produce un clima de inversión más confiable, reduce asimetrías originadas por privilegios informativos, y mejora el proceso de toma de decisiones de los servidores públicos al obligarles a conducirse con mayor responsabilidad.

\section{Transparencia.}

Constituye una política pública. Es cuando el Estado determina exhibir u ofrecer información sobre su funcionamiento, a efecto de someterse al escrutinio público, siendo sujeto activo, es decir, realiza acciones para promover el conocimiento por parte de la sociedad respecto de su gestión.

Produce efectos como: contener a los funcionarios dentro de su función; fortalecer la confianza ciudadana; favorecer el consentimiento de la sociedad en las

\footnotetext{
${ }^{12}$ http://www.promexico.gob.mx/wb/Promexico/transparencia_y rendicion_de cuentas\#ancla1
} 
decisiones y acciones de gobierno; generar una sociedad más y mejor informada, y repercutir en el ejercicio de un voto más responsable.

Derecho de Acceso a la Información. Es un derecho fundamental, además de una herramienta indispensable en un gobierno democrático e instrumento fundamental en una política de transparencia. El Estado es sujeto pasivo, pues debe permitir al sujeto activo (gobernado) ejercer su derecho.

Se caracteriza porque: no se requiere acreditar interés alguno; no se requiere justificar el uso que dará a la información; el ejercicio del derecho es gratuito; las autoridades son susceptibles de sanción si obstaculizan el ejercicio del derecho, y encuentra límites pero la clasificación de la información es una excepción.

Programa Nacional de Rendición de Cuentas, Transparencia y Combate a la Corrupción $2008-2012$ (PNRCTCC) ${ }^{13}$

Lo que se busca con la implementación de este Programa es fortalecer las prácticas y valores dentro de la función pública con un enfoque de gestión más abierto a la participación ciudadana, honesto, transparente y con una nueva vocación para rendir cuentas sobre las acciones y compromisos que se generen con la ciudadanía. Asimismo, se persigue una mejor coordinación entre las instancias responsables del combate a la corrupción. Los seis objetivos estratégicos que se plantean en el Programa y que contribuyen a la alineación de los ejes institucionales del Plan Nacional de Desarrollo 2007-2012 son:

1. Consolidar una política de Estado en materia de información, transparencia y rendición de cuentas.

\footnotetext{
${ }^{13}$ http://www.programaanticorrupcion.gob.mx/prctcc_2008-2012.pdf
} 
2. Fortalecer la fiscalización de los recursos públicos y mejorar el control interno de la Administración Pública Federal para que contribuya a la efectividad y el desempeño de las instituciones.

3. Contribuir al desarrollo de una cultura de apego a la legalidad, de ética y responsabilidad pública.

4. Institucionalizar mecanismos de vinculación y participación ciudadana en el combate a la corrupción y a la mejora de la transparencia y la legalidad.

5. Establecer mecanismos de coordinación de acciones para el combate a la corrupción en la Administración Pública Federal.

6. Combatir la corrupción en instituciones del gobierno federal que participan en la prevención, investigación y persecución de los delitos, así como en la ejecución de las sanciones penales.

El programa establece una estrategia integral donde la transparencia, la rendición de cuentas, la participación ciudadana y la cultura de la legalidad son elementos entrelazados de una política pública renovada de combate a la corrupción, que tiene como finalidad el bienestar y la seguridad de la ciudadanía. Este Programa, conjuntamente con las acciones del Programa Especial de Mejora de la Gestión (PMG) en la Administración Pública Federal, es un reto que se asume con carácter especial y de observancia obligatoria dentro de la Administración Pública Federal.

b) Por su parte en el ámbito de la política, la rendición de cuentas significa "la obligación de todos los servidores públicos de dar cuentas, explicar y justificar sus actos al público, que es el último depositario de la soberanía en una democracia".

Para McLean, la rendición de cuentas es "el requerimiento para que los representantes den cuenta y respondan frente a los representados sobre el uso de sus poderes y responsabilidades, actúen como respuesta a las críticas o requerimientos que les son señalados, y acepten responsabilidad en caso de errores, incompetencia o engaño".

Para Andrea Schedler, la rendición de cuentas en el ámbito político es un concepto de dos dimensiones que denota, por un lado, la obligación de los políticos y funcionarios públicos de informar y justificar sus actos (answerability) y, por el otro, la capacidad para imponer sanciones negativas a los funcionarios y representantes que violen ciertas normas de conducta (enforcement). 
Para Schedler, answerability implica el derecho ciudadano de recibir información y la obligación de los funcionarios de proveerla, pero de manera paralela implica también contar con los mecanismos para supervisar los actos de gobierno. Por su parte, enforcement implica hacer cumplir la ley y sancionar a los gobernantes y representantes que incumplen su mandato a fin de que paguen las consecuencias de sus actos y se active un mecanismo de control preventivo que disuada a potenciales infractores de la ley.

Para Luis F. Aguilar, rendir cuentas significa responsabilidad no en el sentido moral, sino en el social- jurídico de ser responsable de algo ante alguien; implica el sentido de información obligada (no opcional) y de información sobre el cumplimiento o incumplimiento de la responsabilidad. En su opinión, hablar de rendición de cuentas desvinculada de obligatoriedad es un enfoque parcial. "Rendir cuentas es estar por obligación disponible a ser requerido a informar del cumplimiento de responsabilidades.

c) Conviene enfatizar el papel de las sanciones en el concepto de rendición de cuentas. Así, para Schedler, "un sujeto rinde cuentas a otro cuando está obligado a informarle sobre sus acciones y decisiones (pasadas y futuras), justificarlas, y sufrir castigo en el caso de una mala conducta". Para Fearon, "una persona $X$ rinde cuentas a otra persona $Y$, si dos condiciones se cumplen. Primero, hay un entendimiento de que $\mathrm{X}$ está obligada a actuar en nombre de $\mathrm{Y}$. Segundo, $Y$ está facultada por reglas formales e informales para sancionar 0 premiar a X por su desempeño en esta capacidad". Según Dunn, "para que la rendición de cuentas conduzca a la responsividad o sensibilidad de un gobierno, deben existir sanciones y estímulos [...] La remoción de la oficina (no reelección) constituye la más directa sanción [...] Los representantes populares enfrentan otras sanciones además de la remoción del cargo, entre ellas la denuncia, la exhibición, las penas presupuestales y administrativas". 
De otra parte, los expertos ${ }^{14}$ consideran que cinco características de la rendición de cuentas, permiten distinguirla de conceptos semejantes: A saber:

- Delegación. La rendición de cuentas implica delegación de autoridad y responsabilidad de un sujeto "A" llamado mandante o principal a otro sujeto "B" llamado mandatario o agente.

- Representación. La delegación de autoridad significa que el agente (sujeto B) representa al principal (sujeto A) y actúa en su nombre, por lo que debe rendirle cuentas de todo lo que decide y hace en su nombre.

- Responsabilidad mutua. La rendición de cuentas implica una responsabilidad dual. Por un lado, la obligación permanente del agente (B) para ofrecer información detallada de sus actos a su principal (A); y, por el otro, la capacidad y el derecho del principal para monitorear las acciones del agente, detectar posibles incumplimientos y sancionarlo.

- Sanciones. Cuando la rendición de cuentas muestra que el agente (B) incumplió sus responsabilidades, el principal (A) tiene mecanismos para imponerle castigos y sanciones.

- Contrato. La delegación de autoridad del principal al agente implica algún tipo de contrato, ya sea de carácter informal a través de acuerdos verbales o sociales, o de carácter formal a través de leyes y reglas escritas. En el primer caso el contrato informal implica sanciones informales (rechazo comunitario, pérdida de confianza, destierro social), mientras que en el segundo caso las sanciones son formales (desafuero, penas administrativas y/o penales, entre otras). En el ámbito de las relaciones políticas, la mayoría de los contratos son formales y escritos (leyes,

\footnotetext{
${ }^{14}$ Aunque los modelos de principal-agente fueron desarrollados originalmente por economistas (por ejemplo,

A. Alchian y Harold Demsetz, "Production, Information Costs and Economic Organization", en American Economic Review, núm. 62, 1972, y Joseph E. Stiglitz, "Principal and Agent", en John Eatwell, The New Palgrave, Norton, Nueva York, 1989), están siendo usados cada vez más para explicar fenómenos políticos (por ejemplo, Roderick Kiewiet D., y Mathew D. McCubbins, The Logic of Delegation: Congressional Parties and the Appropriations Process, The University of Chicago Press, Chicago, 1991)..
} 
reglamentos, estatutos) y establecen sanciones formales de tipo administrativo, civil o penal en caso de incumplimiento. El contrato superior y más comprehensivo de las democracias son las constituciones, y son complementados con leyes secundarias y reglamentos.

\section{Control y Fiscalización}

Para Luis Carlos Ugalde ${ }^{15}$ son términos que también se usan como sinónimos de rendición de cuentas, a pesar de no serlo. Control y fiscalización son mecanismos para supervisar los actos de gobierno, pero no siempre implican la obligación de los gobernantes para informar de manera periódica sobre sus decisiones y acciones. En ocasiones, el Poder Legislativo inicia motu propio el proceso fiscalizador y la única obligación del Poder Ejecutivo es responder a la información solicitada. En este caso se trata de un proceso unidireccional en el cual el Congreso cuenta con las atribuciones para solicitar información y sancionar en caso de que no se proporcione. Pero esa vigilancia inicia desde el Legislativo sin que el Ejecutivo esté obligado a iniciar dicho proceso. Por ello, el control y la fiscalización deben ser vislumbrados como unos de los mecanismos de un sistema de rendición de cuentas, mismo que abarca, además, otros instrumentos y obligaciones que nacen de los propios gobernantes. Asimismo Ugalde considera en cuanto al concepto de transparencia que también se usa en ocasiones como sinónimo de rendición de cuentas. Precisando al respecto que la

\section{Transparencia}

Es una característica que abre la información de las organizaciones políticas y burocráticas al escrutinio público, mediante sistemas de clasificación y difusión que reducen los costos de acceso a la información del gobierno. Sin embargo, la transparencia no implica un acto de rendir cuentas a un destinatario específico,

\footnotetext{
${ }^{15}$ Ugalde, Luis Carlos. "Rendición de Cuentas y Democracia: El Caso de México", Instituto Federal Electoral México 2002,Primera edición ISBN: 970-695-018-4, pp.16
} 
sino la práctica de colocar la información en la "vitrina pública" para que aquellos interesados puedan revisarla, analizarla y, en su caso, usarla como mecanismo para sancionar en caso de que haya anomalías en su interior. La transparencia es un instrumento de un sistema global de rendición de cuentas, mas sería impreciso usarlo como sinónimo de aquél.

Hechas estas precisiones, para efectos de este ensayo tomaremos el concepto de transparencia como la característica que debe revestir la información de las organizaciones políticas y burocráticas que se presenta al escrutinio público, mediante sistemas de clasificación y difusión la cual (información) una vez revisada, analizada y, en caso de anomalías pueda ser utilizada como mecanismo para sancionar. El concepto de rendición de cuentas que se define como "la obligación permanente de los mandatarios o agentes para informar a sus mandantes o principales de los actos que llevan a cabo como resultado de una delegación de autoridad que se realiza mediante un contrato formal o informal y que implica sanciones en caso de incumplimiento. Los mandantes o principales supervisan también a los mandatarios o agentes para garantizar que la información proporcionada sea fidedigna.

\section{Panorama estructural}

Indubitablemente, entre los actos más importantes del gobierno figuran los relacionados con la hacienda pública, y por ello es importante garantizar a los contribuyentes, que aportan una porción -sin adjetivos- de sus riquezas para el sostenimiento del Estado, la certeza de que el producto de sus contribuciones se emplea en los proyectos o planes que le han autorizado legalmente. 
En este sentido Don Jorge Fernández Ruiz atinadamente señala en su magnífica obra de Derecho Administrativo Local $^{16}$ que uno de los peligros permanentes en todo Estado es la posible corrupción de sus agentes; el propósito de prevenirla y evitarla demanda el ejercicio de la función pública de fiscalización o control que es descrita como la actividad técnica y esencial del ente estatal dirigida a vigilar, verificar, comprobar y evaluar las actividades de los órganos, dependencias y servidores públicos a cuyo cargo está el manejo de los fondos, valores, recursos, bienes y derechos del propio Estado. Su objetivo: determinar si su actuación se hizo con apego a la normativa jurídica vigente. Su finalidad: a) poder corregir tales desviaciones, a efecto de alcanzar los fines, objetivos y metas previstos así como b) en su caso, la posibilidad de su sanción. A lo anterior habría que agregar un tercer elemento la intervención de los mandantes o principales quienes supervisan también a los mandatarios o agentes para garantizar que la información proporcionada sea fidedigna: En este sentido, el control y vigilancia de la administración pública se da desde el exterior y desde el interior de la misma administración; en el primer caso, por medio de los órganos jurisdiccionales ${ }^{17}$, del órgano Legislativo ${ }^{18}$, del órgano de fiscalización superior, que en el ámbito federal de nuestro país es la Auditoría Superior de la Federación y sus homólogas ${ }^{19}$ en el

\footnotetext{
${ }^{16}$ Fernández Ruiz Jorge, Salgado Ledesma, Erendira Derecho Administrativo del Estado de Sinaloa, Ed. Porrúa México 2009 pp.47
}

\begin{abstract}
${ }^{17}$ En lo que concierne al control externo de la administración pública por medio de los órganos jurisdiccionales, puede ser de dos tipos: el control de constitucionalidad y el control de legalidad, que admiten diversas modalidades, como son la controversia constitucional, el amparo administrativo, y el contencioso administrativo; los dos primeros se dilucidan en el ámbito federal, en tanto que el contencioso administrativo, en el ámbito federal y en el local del Estado de Sonora.

${ }^{18}$ En Sonora, el control y fiscalización de la administración pública, tanto estatal como municipal, así como a los organismos constitucionales y legales autónomos, y a cualquier persona de derecho público o privado que recaude, administre, maneje, custodie, aplique o ejerza recursos públicos, por parte del Congreso del estado, están previstos principalmente en el artículo 64, fracciones: XXII, XXIV, XXIV BIS, XXV, XXVI, XXVII, XXVII Bis, XXXII y XXXII Bis de la Constitución local, que confieren a dicho órgano legislativo las facultades para llevar a cabo el control y la fiscalización: En consecuencia, corresponde al Congreso legislar sobre la materia y fiscalizar a través del Instituto Superior de Auditoría y Fiscalización.
\end{abstract}

${ }^{19}$ Existe en el estado de Sonora un órgano técnico que desde el Poder Legislativo revisa la actuación de los tres poderes del estado (Ejecutivo, Legislativo y Judicial), se trata del Instituto Superior de Auditoría y Fiscalización del Estado de Sonora, previsto en la fracción XXIV Bis y XXXII Bis-A del Artículo 64 de la Constitución Política del Estado de Sonora, al que se le atribuye el ejercicio de la función fiscalizadora.

El Instituto Superior de Auditoría y Fiscalización del Estado de Sonora, es un órgano constituido con autonomía presupuestaria, técnica y de gestión para establecer su organización interna, funcionamiento y resoluciones; con las facultades legales como Órgano de Fiscalización Superior del Congreso del Estado para realizar la auditoría de los Estados Financieros, la revisión y fiscalización de la Cuenta Pública del Estado y de los Municipios y demás sujetos fiscalizados, así $\sim 32 \sim$ 
como las demás actividades necesarias para el eficaz sujetos cumplimiento de sus funciones y competencia de acuerdo con lo establecido en el Artículo 67 de la Constitución Política del Estado Libre y Soberano de Sonora, la Ley Secundaria y su Reglamento, así como las demás disposiciones legales aplicables.

Principales funciones, según el artículo 67 constitucional:

Las atribuciones del Instituto Superior de Auditoría y Fiscalización del Estado de Sonora, serán específicas y generales. Serán atribuciones específicas:

A) Revisar los estados financieros trimestrales y anuales del Gobierno del Estado y de los Municipios, que para dicho particular deberán presentarse al Instituto por los referidos niveles de gobierno, para el exclusivo efecto de formular observaciones si las hay, en su caso, darles seguimiento, con la finalidad de colaborar con las autoridades administrativas y penales en el cumplimiento de las disposiciones relativas al manejo de fondos públicos;

B) Revisar y fiscalizar anualmente las cuentas públicas del año inmediato anterior que deberán presentar los tres Poderes del Estado y los Municipios

C) Revisar anualmente las cuentas públicas del año inmediato anterior correspondientes a los organismos constitucionalmente autónomos, quienes deberán presentarlas auditadas por despacho externo de contadores designado por el propio organismo.

D) Fiscalizar los ingresos y egresos, así como el manejo, custodia y aplicación de los recursos públicos de los Poderes del Estado y de los Ayuntamientos, incluidos todos los entes, organismos, entidades, dependencias, fideicomisos, fondos y cualesquier otra oficina de cualquier naturaleza que de cualquier modo dependa o forme parte de las entidades estatales o municipales, e igualmente los recursos públicos ejercidos por particulares, incluyéndose para dicho efecto las atribuciones necesarias para verificar que los ejercicios correspondientes se encuentren ajustados a los criterios, planes y programas especificados en los presupuestos aprobados respectivamente.

E) Entregar al Pleno del Congreso, por conducto de la Comisión de Vigilancia referida en la fracción XXXII Bis del Artículo 64 de la Constitución Local y el Artículo $6^{\circ}$ anterior de la presente Ley, los resultados de la revisión de las cuentas públicas a más tardar el 30 de agosto del año de su presentación, incluyéndose en dicha entrega los informes de la revisión, un apartado correspondiente a la verificación del cumplimiento de objetivos de los programas y demás información que determine las Leyes Secundarias;

F) Investigar los actos u omisiones relativos a irregularidades o conductas ilícitas en el ingreso, egreso, manejo, custodia y aplicación de recursos públicos, los actos, contratos, convenios, concesiones u operaciones que los sujetos fiscalizados celebraron o realizaron, se ajustaron a la legalidad, y si no se causaron daños o perjuicios en contra de las haciendas públicas estatal o municipales; al patrimonio de las demás entidades u organismos de la administración pública estatal o municipal, pudiendo para este efecto, realizar toda las diligencias que resulten conducentes, incluyéndose visitas domiciliarias a particulares o terceros que hubieren contratado o que hubiesen fungido como proveedores de bienes o servicios a la autoridad estatal o municipal con el exclusivo propósito de compulsar las transacciones correspondientes y requiriendo la documentación justificativa y comprobatoria que las sustente, en los términos y con las formalidades previstas para los cateos.

G) Determinar y ejecutar las medidas conducentes a la recuperación de los daños y perjuicios que afecten al erario por el ejercicio indebido o equivocado de recursos públicos, fincando directamente a los responsables las indemnizaciones y sanciones correspondientes $\mathrm{y}$, en su caso, denunciar ante las autoridades competentes las responsabilidades administrativas y penales por el o los delitos que presumiblemente aparezcan cometidos; de todo lo cual informará al pleno del Congreso por conducto de la Comisión referida en la fracción XXIII Bis del Artículo 64 de la Constitución Local.

H) Ejercer las atribuciones referidas en los apartados D, F y G con respecto a los ejercicios presupuestales de los organismos constitucionalmente autónomos solamente en los casos en que, a propuesta de la Comisión, lo determine el Pleno del Congreso por votación calificada de dos tercios de los Diputados presentes en la sesión.

Según el Artículo $3^{\circ}$ de la Ley de Fiscalización Superior para el Estado de Sonora, son sujetos de fiscalización aquellos entes públicos que reciban, administren o ejerzan total o parcialmente y bajo cualquier título recursos públicos, quedando sujetos a la observancia y cumplimiento de las disposiciones de la presente ley, en el ámbito de:

I. El Poder Ejecutivo, las dependencias de la administración pública directa y las entidades paraestatales, las unidades de apoyo adscritas directamente al Ejecutivo del Estado y los organismos públicos constituidos por el propio Ejecutivo;

II. El Poder Judicial y los órganos que lo conforman, cualquiera que fuere su organización;

III. El Poder Legislativo, sus dependencias y cualquiera de sus órganos, cualquiera que fuere su organización;

IV. Los órganos constitucional o legalmente autónomos;

V. Las universidades e instituciones públicas de educación superior y organizaciones con registro oficial que reciban recursos públicos;

VI. Los ayuntamientos y cualquier autoridad, dependencia o entidad de la administración pública municipal; y

VII. Cualquier persona física o moral que reciba, administre o ejerza total o parcialmente y bajo cualquier título recursos públicos.

De igual manera, los órganos autónomos, como la Comisión Estatal de Derechos Humanos y el Consejo Estatal Electoral tienen, cada uno, su propia estructura orgánica un órgano investido de la facultad de ejercitar la función fiscalizadora o de control.

En cuanto al tema de control y fiscalización de los recursos que manejan los partidos políticos, como instituciones de derecho público, la Constitución estatal dispone en el artículo 22 lo siguiente:

...El financiamiento público de los partidos políticos y de sus campañas electorales deberá prevalecer sobre los privados, para tal efecto, el Consejo Estatal Electoral integrará un órgano de fiscalización que controlará y vigilará el uso de todos los recursos con que cuenten, sean de origen privado o público y propondrá las sanciones que deban imponerse por el uso indebido de estos recursos, de conformidad con lo que establezca la Ley. 


\section{nivel local, y del ombudsman ${ }^{20}$. Desde el interior, nuestra administración pública federal ejerce la función de fiscalización a través de la Secretaría de la Función}

La Ley establecerá un sistema de medios de impugnación de los que conocerán los organismos electorales y un Tribunal Estatal Electoral y de Transparencia Informativa. Dicho sistema dará definitividad a las distintas etapas de los procesos electorales y garantizará que los actos y resoluciones se sujeten, invariablemente, al principio de legalidad. Sus sesiones serán públicas.

${ }^{20}$ En Sonora, la institución del ombudsman se materializa a través de la Comisión Estatal de los Derechos Humanos, como un organismo público, de carácter autónomo, dotado de personalidad jurídica y patrimonio propios, que tiene por objeto la protección, observancia, promoción, estudio y divulgación de los derechos humanos establecidos por el orden jurídico mexicano, con competencia para conocer de quejas en contra de actos u omisiones de naturaleza administrativa provenientes de autoridades o servidores públicos del estado o de sus municipios que violen los derechos humanos establecidos por la Constitución federal y en las leyes que de ella emanen, así como los contenidos en los instrumentos internacionales suscritos y ratificados por los órganos correspondientes del poder federal, según previenen los artículos 102, apartado B de la Constitución Política de los Estados Unidos Mexicanos, y los artículos 1, 2, 3, 6 y 7 de la Ley que crea la Comisión Estatal de Derechos Humanos; más no será competente cuando se trate de asuntos en que las autoridades públicas involucradas sean federales, cuando versen cuestiones jurisdiccionales de fondo, cuando se traten conflictos de carácter laboral, cuando las reclamaciones se refieran a actos y resoluciones de organismos y autoridades electorales; sin embargo, sí tendrá competencia para conocer de quejas o inconformidades contra actos u omisiones de autoridades judiciales estatales o de los Tribunales Administrativos que presuntamente hayan violado derechos humanos, solamente cuando dichos actos u omisiones tengan carácter estrictamente administrativo.

Sobre el particular, cabe citar lo establecido por el Tribunal Colegiado del Vigésimo Segundo Circuito, quien expresó que Partiendo de la base de que la Comisión Estatal de Derechos Humanos, no es una autoridad, dado que no dispone de la fuerza pública para hacer cumplir sus determinaciones, sino que se trata de un organismo técnico-jurídico, que tiene la función de defender y vigilar los derechos humanos, así como promover, difundir y coordinar la enseñanza, estudio y capacitación de la cultura del respeto por los derechos humanos, de conformidad con el artículo 2o. de su ley orgánica; ello permite considerar, que al aceptar sus recomendaciones las autoridades a quienes van dirigidas, no puede darse por hecho que ante el referido organismo se brindó al funcionario implicado, la garantía de audiencia consagrada en los artículos 14 y 16 constitucionales, puesto que en tales preceptos de la Carta Magna se estipula que esa garantía habrá de ser brindada, por los tribunales previamente establecidos o la autoridad competente; sin que la Comisión Estatal de Derechos Humanos pueda conceptuarse en alguna de estas hipótesis. De suerte que la garantía de audiencia habrá de concederse al funcionario implicado, ante la autoridad que, de acuerdo con la ley, se encargue de calificar las posibles conductas indebidas de los funcionarios públicos.

En razón de su autonomía orgánica y funcional, las actividades y criterios de los directivos de la Comisión de Derechos Humanos del Estado de Sonora, no estarán supeditados a ninguna autoridad pública, precisándose en la Ley que la crea, como ya se señaló, que no forma parte de la administración pública estatal, y entre sus atribuciones destacan las siguientes, que inciden en el control de la administración pública del estado y de sus municipios:

--Recibir quejas de presuntas violaciones a derechos humanos;

--Conocer e investigar a petición de parte, o de oficio, presuntas violaciones de derechos humanos en los siguientes casos:

a) Por actos u omisiones de autoridades administrativas de carácter estatal o municipal.

b) Cuando los particulares o algún otro agente social cometan ilícitos con la tolerancia o anuencia de algún servidor público o autoridad, o bien cuando estos últimos se nieguen infundadamente a ejercer las atribuciones que legalmente les correspondan en relación con dichos ilícitos, particularmente tratándose de conductas que afecten la integridad física de las personas;

--Formular recomendaciones públicas autónomas, no vinculatorias, y denuncias y quejas ante las autoridades respectivas, en los términos establecidos por el artículo 102, apartado B, de la Constitución Política de los Estados Unidos Mexicanos; --Procurar la conciliación entre los quejosos y las autoridades señaladas como responsables, así como la inmediata solución de un conflicto planteado, cuando la naturaleza del caso lo permita;

--Impulsar la observancia de los derechos humanos en el estado;

--Proponer a las diversas autoridades del estado y de los municipios, que en el ámbito de su competencia, promuevan los cambios y modificaciones de disposiciones legislativas y reglamentarias, así como de prácticas administrativas, que a juicio de la comisión redunden en una mejor protección de los derechos humanos;

--Promover el estudio, la enseñanza y divulgación de los derechos humanos en los ámbitos estatal y municipal;

--Expedir su reglamento interno;

--Elaborar y ejecutar programas preventivos en materia de derechos humanos;

--Supervisar el respeto a los derechos humanos en el sistema penitenciario y de readaptación social del estado;

--Formular programas y proponer acciones, en coordinación con las dependencias competentes, que impulsen el cumplimiento en el estado de los tratados, convenciones y acuerdos internacionales signados y ratificados por México en materia de derechos humanos;

--Proponer al ejecutivo estatal, en los términos de la legislación aplicable, la suscripción de acuerdos interinstitucionales, en materia de derechos humanos;

--Las demás que le otorguen la presente ley y otros ordenamientos legales.

$$
\sim 34 \sim
$$


Pública, de la Secretaría de Hacienda y Crédito Público, de las contralorías internas de cada una de sus dependencias y entidades, así como por medio del recurso administrativo. Situación análoga ocurre en la administración pública del Distrito Federal en las de los estados ${ }^{21}$ y en las de sus municipios.

\author{
Además, el control se da de arriba hacia abajo y de abajo hacia arriba, de \\ dentro hacia fuera de la administración pública y de fuera hacia dentro de la \\ misma administración ${ }^{22}$;
}

\title{
Hasta aquí, hemos descrito panorámicamente las estructuras federal y local del estado de Sonora en relación al ejercicio de la función de fiscalización, vigilancia,
}

La Comisión para un mejor desempeño de sus funciones contará con un Consejo que estará integrado por el Presidente de la Comisión y seis personas de prestigio reconocidas en la sociedad sonorense, que sean mexicanos en ejercicio pleno de sus derechos ciudadanos y que no desempeñen cargo, empleo o comisión como servidores públicos. El Presidente de la Comisión, es nombrado por el Congreso del Estado de Sonora, por las dos terceras partes de sus Diputados integrantes. Para el nombramiento respectivo, se valora previamente las opiniones de la sociedad sonorense, de acuerdo a los procedimientos que el Congreso determina, con base en su propia normatividad interna. El Presidente de la Comisión dura en su encargo cuatro años y puede ser ratificado exclusivamente para un segundo período. El Presidente de la Comisión es el representante legal de la misma, y el responsable de la organización y administración de la institución. En su actuación el Presidente de la Comisión, los Visitadores Generales y los Adjuntos en sus actuaciones tendrán fe pública, para certificar la veracidad de los hechos en relación con las quejas, presentadas ante la Comisión. El Consejo de la Comisión es un órgano de decisión, pues entre otras facultades, aprueba el Reglamento Interno de la Comisión y establece los lineamientos generales de actuación de la Comisión. Realiza sesiones ordinarias y extraordinarias y sus decisiones se toman por mayoría de votos de sus miembros presentes.

${ }^{21}$ En el estado de Sonora, es a través de la Secretaría de la Contraloría General que se aplica el sistema integral de control y desarrollo administrativo tanto a las dependencias -secretarías y Procuraduría General de Justicia-, los organismos descentralizados, las empresas de participación estatal mayoritaria y fideicomisos públicos con que cuenta la administración pública estatal, y que, en ejercicio de la función de fiscalización o control, trata de descubrir sus fallas y adoptar las medidas necesarias para corregirlas.

En los términos del artículo 26, de la Ley Orgánica del Poder Ejecutivo del Estado de Sonora, las facultades y obligaciones de la Secretaría de la Contraloría General, se detallan en el capítulo cuarto, intitulado, De la Administración Pública, en el que se examina la competencia de las dependencias de la administración pública directa, de conformidad con la Ley Orgánica del Poder Ejecutivo del Estado de Sonora, en vigor.

Así mismo, en el Título Tercero, "De la Administración Pública Paraestatal" capítulo cuarto, "Del Control, Vigilancia y Evaluación de las Entidades Paraestatales" en su artículo 57 se establece:

"ARTICULO 57.- Las funciones de control y evaluación de las entidades paraestatales estarán a cargo de los órganos de control y desarrollo administrativo, los cuales dependerán jerárquica, administrativa y funcionalmente de la Secretaría de la Contraloría General.

Los Comisarios Públicos Oficiales y Comisarios Públicos Ciudadanos, designados por la Secretaría de la Contraloría General, ejercerán las funciones de vigilancia de las entidades paraestatales.

El Comisario Público Ciudadano percibirá los estímulos que se fijen anualmente en el presupuesto de egresos de la Secretaría de la Contraloría General.

Los titulares de los órganos de control y desarrollo administrativo y los Comisarios Públicos, participarán con voz en las reuniones de los órganos de gobierno de las entidades"

${ }^{22}$ A este respecto, Joan Subirats, hace notar: No podemos aceptar una única perspectiva de control, de arriba abajo, existen, además otras perspectivas tanto o más decisivas: de "abajo a arriba'”(en flujos de información, por ejemplo), de "dentro" de la administración hacia "fuera" (en el control de los recursos o servicios que se distribuyen), o de "fuera" a "dentro" (en las presiones de grupos de clientes o de interés en conseguir más recursos a cambio de ciertas concesiones o respaldos políticos o de otro tipo Joan Subirats Joan Análisis de políticas públicas y eficacia de la administración, Madrid, INAP, 1989, p. 128. 
control y evaluación de la actuación de las autoridades gubernamentales en el desempeño de las funciones administrativa, legislativa y judicial. Por lo que a continuación desarrollamos el objetivo de nuestra participación

\section{Objetivo}

Análisis académico crítico reconstructivo y eventualmente propositivo acerca de lo que hacen, no hacen y en su caso debieran hacer las instancias encargadas del control interno de la administración pública local y el obligado referente federal, mostrando los procedimientos propuestos en tres casos a cambio de los simples o lineales de control instrumental que actualmente suelen operar de acuerdo a la normatividad vigente.

\section{Control Gubernamental ${ }^{23}$}

\section{Las instituciones públicas y en general la administración pública se ha} transformado en los últimos años en el mundo, y particularmente en América Latina, "Las instituciones democráticas están siendo cada vez mas abusadas,

\footnotetext{
${ }^{23}$ La rendición de cuentas es un concepto global que acepta clasificaciones de acuerdo a diversos criterios. Por ejemplo, se puede clasificar de acuerdo al sujeto de la rendición, dando diversos tipos, entre ellos la rendición legislativa, gubernamental, burocrática, judicial y militar. La clasificación más sugerente sobre rendición de cuentas fue elaborada por Guillermo O'Donnell, que la divide en horizontal y vertical. De acuerdo a las convenciones de uso que se han establecido en la academia, lo horizontal se refiere a relaciones de control entre agencias de Estado, lo vertical a exigencias de rendición de cuentas de la sociedad civil hacia el Estado. Sin embargo, hay que llamar la atención a una limitante obvia de esta distinción. Concibe la rendición de cuentas dentro de los confines estrechos de sistemas políticos nacionales. La rendición de cuentas vertical describe una relación entre desiguales (rendición burocrática en la que un superior jerárquico trata de controlar a sus subordinados, o bien, la rendición electoral en la cual los votantes juzgan y vigilan a los representantes). A diferencia de la rendición de cuentas horizontal, en la cual la fiscalización tiene sanciones vinculantes penal o administrativamente, la rendición de cuentas vertical sólo cuenta, en primera instancia, con sanciones morales o simbólicas. No hay multas económicas ni encarcelamientos. Las organizaciones sociales y los medios de comunicación realizan investigaciones, pronunciamientos y juicios dirigidos a exhibir al servidor público que ha faltado a la honestidad, la libertad o la transparencia. Sin embargo, ambos sistemas de rendición de cuentas, el horizontal y el vertical, son complementarios. Las acciones legales y administrativas son fundamentales para prevenir, sancionar y, eventualmente, reparar el daño ocasionado por un acto ilícito o corrupto. Y las acciones de rendición de cuentas vertical pueden detonar en un periodo ulterior la vigilancia horizontal.
} 
están siendo cada vez más frágiles ante los embates de los políticos en el poder $^{\prime 24}$, lo cual nos lleva a reflexionar cuan necesario y pertinente se hace en nuestros tiempos, el diseño y reorientación del concepto de sistemas de control al de control de sistemas, esto es, se torna patente el tránsito de los tradicionales sistemas de control gubernativo dominante, hacia el control de sistemas institucionales desde la base ciudadana.

Para facilitar la comprensión de lo anterior se requiere re-pensar el concepto de "sistemas de control" en una intencionalidad de ciudadanizarlo y operacionalizarlo, de hacerlo accesible para su aplicación al mundo real que vive el ciudadano, para llegar a concebir lo que llamamos aquí el "control de sistemas".

Cuando se hace referencia al concepto de "Sistemas de Control", sólo haciendo un juego de palabras tratando de ser creativos y hasta propositivos, podríamos llegar a pensar al mismo tiempo la expresión: "Control de Sistemas"... ¿Porqué? Sencillamente porque el control puede concebirse para dos efectos:

Sistemas de Control.- Para el aseguramiento de que lo previsto (conductas, acciones, políticas, costumbres, pautas, normas, etc.), se esté realizando de acuerdo a lo planeado o previsto y que el status quo o el sistema objeto de control no falle y se mantenga estable.

Control de Sistemas.- Para que sean controladas las instituciones en términos de los sistemas que se operan en ellas y por ellas.

Antes de preguntarnos o de realizar cuestionamientos en torno al control, es pertinente preguntarnos... control... ¿para qué? El resto de las preguntas se

\footnotetext{
${ }^{24}$ Guerra, Gabriel, (2009), A un mes del golpe en Honduras, entrevistado por Carmen Aristegui, CNN en Español, julio 28
} 
presentan en consecuencia. Es como fijar una posición ideológica, por ejemplo en cuanto a controlar para el servicio de ¿quién?

El propósito del control desde ese punto de vista podría ser de utilidad para servir al status quo, para servir a la clase en el poder, a los líderes de partidos políticos, a dirigentes de cámaras empresariales o poseedores del poder económico; puede también ser de utilidad al orientarse para controlar conductas de las masas y servir a quienes gobiernan, así como también podría simplemente ser orientado para controlar la disposición y manejo de recursos.

Esta última podría ser la opción más simple, lineal, técnica e irrelevante, porque finalmente esta opción se orienta a una visión economicista, o sea de economías simples en la administración de recursos, los cuales finalmente habrán de ser utilizados para algo, esto es, si se controla desde el punto de vista de evitar la corrupción o el manejo de recursos públicos con fines de intereses personales, y al mismo tiempo para lograr ahorros o la disposición eficiente de los mismos, finalmente esos recursos excedentes o sostenidos "en números negros" habrán de ser empleados para algo, con una finalidad ulterior.

Después de aclarar entonces esa pregunta acerca de "control... ¿para qué?", la demás se responden en consecuencia: ¿con qué, ¿Quién?, ¿Cómo?, ¿Cuánto?, ¿Cuándo?, ¿dónde?, etcétera. Así, el eje central de esa pregunta girará en torno a una posición ideológica cuasi-neutral que nos lleva a la respuesta siguiente: Controlar para generar efectos de satisfacción ciudadana.

De esa manera, toda idea de control de lo gubernamental de manera endógena y exógena estaría orientada con esa postura. Controlar para lograr efectos de satisfacción generalizada de la ciudadanía implica por ejemplo, lo siguiente: 
- Controlar la seguridad pública y la seguridad nacional para generar tranquilidad

- Controlar bienes para una distribución más equitativa y justa de la riqueza

- Controlar las finanzas públicas para asignaciones de mayor y mejor impacto

- Controlar los procesos legislativos y regulatorios para mejorar la justicia

- Controlar la administración pública en el ejercicio de sus atribuciones

- Controlar inventarios, bienes, archivos, sistemas de comunicación, etc. para hacer más ágil y expedita la prestación de servicios públicos

Cuando se pierde de vista lo anterior se realizan acciones por inercia tales como la de controlar por controlar, o para justificar la existencia de plazas u organismos innecesarios, para justificar mayores asignaciones presupuestales o para monitorear sin sentido alguno el comportamiento de empleados y ciudadanos.

Con el control de los sistemas gubernamentales se pretende lograr que el resto de sistemas institucionales operen con efectos de satisfacción ciudadana, esto es, que cada acción y recurso genere impactos efectivos, satisfacción efectiva o efectividad en la credibilidad y confianza de los contribuyentes y de la sociedad en general, y no sólo lo que tradicional y culturalmente se considera eficiencia y/o eficacia en la gestión gubernamental. A propósito de errores culturales históricos, el considerar que dentro de control interno solo existe el control vertical que es un proceso en cascada, esto es, de arriba abajo, de los jerárquicos superiores hacia los inferiores. El control vertical como bien se reconoce por la academia, también es una función factible de ser desplegada desde las jerarquías de los servidores públicos más modestos y sobre todo por la ciudadanía misma (hacia arriba), porque son quienes cotidianamente se enfrentan a los "comos" se hacen y debieran realizarse las acciones más sencillas mejorando tiempos, movimientos y efectos de satisfacción. 
En otras palabras, es empoderar o dotar de competencias a todo individuo integrado a alguna organización ciudadana facultándolo para vigilar e intervenir en decisiones y hasta ejecución de obras y servicios de gobierno, lo cual a la manera de Foucault ${ }^{25}$ (2001), permitiría reproducir en cada ciudadano el saber y el poder conferido de vigilar y promover en su caso, el sancionar ${ }^{26}$.

Una organización gubernamental en tanto institución (la cual opera procesos y en general puede ser también concebida como un sistema), tiene la responsabilidad primigenia de revisar y mantener actualizados sus sistemas internos, para lo cual su orientación básica es hacia el control de sistemas y no hacia la operación de sistemas de control.

Hablar de control es referirse a procesos de verificación, mejoramiento y de reorientación en su caso, de los sistemas adjetivos, directivos, sustantivos, de regulación administrativos o de apoyo y operativos para servir desde todas y cada una de las instituciones gubernamentales al ciudadano, para llegar al logro de efectividad en la satisfacción ciudadana con los procesos del poder público.

A pesar de lo anterior, no se puede soslayar que suelen persistir sesgos, o presentarse acciones conscientes o involuntarias de empleados de instituciones públicas, que en el desempeño de sus roles se olvidan de orientar su función y

\footnotetext{
${ }^{25}$ Foucault, Michel, Vigilar y castigar. Nacimiento de la prisión, México. 2001. Editorial Siglo XXI, 31ª. Ed., pp220 p.

${ }^{26}$ Vivir de la cárcel, sin vivir en ella fue la labor de Bentham, -recordemos, que le fue concedido un premio económico por su invento-. Pero además, el panóptico (toda visión) se muestra con dos rostros; el castigo y la educación. Ya que nuestro autor se pregunta por lo que es una prisión, contestándose que "...es una mansión en que se priva a ciertos individuos de la libertad de que han abusado, con el fin de prevenir nuevos delitos, y contener a los otros con el terror del ejemplo; y es además una casa de corrección en que se debe tratar de reformar las costumbres de las personas reclusas, para que cuando vuelvan a la libertad no sea esto una desgracia para la sociedad ni para ellas mismas" por su parte Foucault simboliza con él un modelo de sociedad disciplinaria que aparece fines del siglo XVIII con el iluminismo; s. De lo que se trata es utilizar de la mejor manera el tiempo para producir (CONDUCTAS DESEADAS) o para cualquier actividad que sea vista productivamente. Además, la noción básica sobre el poder que tiene Foucault, lleva a la descentralización del mismo que cambia la tradicional noción de soberanía. Cada ciudadano se convierte en vigilante, con su mirada y su palabra, reproduciendo con ello el saber y el poder.
} 
esfuerzos cotidianos al usuario, integrándose a pequeñas mafias, partidos o grupos de interés que anulan los nobles propósitos originales de toda institución creada.

Para ello se propone el control de sistemas, asimismo, para integrar en un todo sistémico u holístico a ciudadanos.

Por virtud de esa complejidad, las Ciencias Sociales auxilian en la comprensión de la fenomenología del control, ya que permiten desde una visión holística o totalizadora, la comprensión integral de los procesos de cada institución.

Controlar sistemas desde una perspectiva ciudadana y científica sería entonces una opción interesante, la cual no esperaría a que surgiesen sistemas de control, esto es, a que hubiere en su caso sesgos incluso de diseño de sistemas o de instituciones que exija la operación de acciones de control desde arriba, ya que se realizarían desde la visión de quienes esperan ser servidos por ellas, ser beneficiados por esos sistemas, por esas instituciones.

Recordemos que los sistemas de control, a diferencia del control de sistemas, son procesos de vigilancia desde arriba a fin de evitar variaciones en lo prescrito, en lo normado, mientras que el control de sistemas se concibe como la acción que desde abajo, aportan los operadores y beneficiarios y que permite desde el diseño de sistemas hasta la introducción de mejoras e innovaciones en los mismos, para lo cual se hace pertinente y necesario llevar a cabo acciones de gestión.

En gran parte de los casos, el control obedece al principio administrativo de orden, esto es, a lograr que cada cosa esté en su lugar y que haya un lugar para cada cosa, sin embargo, otras situaciones obedecen al principio político de dominación, mientras que otras al principio sociológico antinómico y otras más al psicológico de condicionamiento o al comunicativo del saber. Se trata de concebir 
la función de control ${ }^{27}$ como fenómeno complejo, como sistema, y no sólo como técnica en boga. Se trata de comprender la multidimensionalidad de la intención controladora y el para qué de ella, a fin de estar en posibilidad de repensarla y hasta de rediseñarla, fortalecerla en su caso o eliminar fallas o partes significativas que en lugar de auxiliar a las instituciones gubernamentales en su efectividad, podrían tender a entorpecer sus flujos

De otra parte, es preciso señalar que las Ciencias Sociales también producen tecnología como la referida y requerida de control; citando al Dr. Pablo González Casanova, por ejemplo, “...las técnicas científicas de control social han venido aumentando cada vez más en importancia y efectividad (...) haciendo de ellas las técnicas dominantes de los países dominantes"28

Haciendo un paréntesis, revisaremos a continuación el contexto mundial actual por lo que resulta pertinente ${ }^{29}$ hacer alusión a la fenomenología de crisis mundial, tema principal en dos foros mundiales simultáneos: el Foro Económico Mundial, llevado a cabo en Davos, Suiza, cuyo lema fue "Estructurar el mundo tras la crisis", y el Foro Social Mundial llevado a cabo en Belén do Brasil, durante el mes de enero de 2009. Durante el primero vale la pena rescatar una breve pero sustanciosa frase textual dicha por Merkel Ángela, Canciller alemana durante su participación en la tercer ronda, señalando que

"Con un capitalismo ilimitado puede haber riesgos...los excesos se tienen que impedir"30, lo cual no deja lugar más que a cuestionamientos serios en torno al descontrol no sólo de la economía, sino del orden mundial.

27

${ }^{28}$ González Casanova, Pablo, (1987), La falacia de la investigación en ciencias sociales, Edit. Océano, México. pp121.

${ }^{29}$ Morales Zamorano M A, Banda Castro A L, González Beltrones AV, Valenzuela Miranda GA, Avendaño Enciso A, Sistema de Control Socio-Gubernamental. Ed. SEP-PIFI-UNISON, México 2010.pp86

30.- .- Merkel Ángela, (2009), Canciller alemana durante su participación en la tercer ronda del Foro Económico Mundial, Davos, Suiza, tomado de http://www.eluniversal.com.mx/finanzas/68878.html 
Mientras tanto, durante el segundo evento mundial, los Presidentes asistentes (de Venezuela, Brasil, Argentina, Bolivia, Paraguay y Ecuador), se pronunciaron conjuntamente por la idea de que "otro mundo es posible y necesario"31. Al respecto de estas casi coincidentes formas de aprehender una realidad en crisis mundial, aunque los primeros en una intencionalidad reformista y los segundos más transformadora, Luhmann nos advierte que la sociedad no crece como la levadura, sino que vuelve más complejos unos ámbitos funcionales y deja que otros se deterioren ${ }^{32}$; esto indica que al poder ciudadano o poder social se le ha dejado deliberadamente a que se deteriore, haciendo tan complejo y hasta incontrolable un sistema económico, que no se dio lugar a que aquél velara por un legítimo y efectivo funcionamiento del segundo sistema.

En la historia del ejercicio del poder de controlar, de operar sistemas de control, la base ciudadana ha sido la más desfavorecida.

Hablar de estructuras es hablar de instituciones, entre ellas las normativas o jurídicas que propician el fortalecimiento de un poder y que los otros estén a la expectativa de ello para también restituirse beneficiados. El crecimiento económico ha sido así, sin desarrollo, sin un bienestar que sea garante de una vida digna para los ciudadanos, sobre todo para las grandes masas o mayorías más desposeídas y que tienden a legitimar las estructuras de poder.

Justamente, conviene revisar escenarios contextuales comparados en diversas regiones y países a fin de comprender el estado del arte y hacia donde apunta la idea del control de sistemas en instituciones gubernamentales. En este contexto cabe señalar que haber generalizado la creencia de que la lucha contra la corrupción es sólo contra cinco elementos: crimen organizado y narcotráfico, lavado de dinero, tráfico de influencias así como abuso de poder, soborno e impunidad, lo cual ha mantenido con una tela de humo que cubre al mismo

\footnotetext{
31.- Información tomada de http://www.jornada.unam.mx/ultimas/

32.- Luhmann, Niklas, (1998), Teoría de la sociedad, p. 187 
concepto de corrupción en tanto descomposición, corrosión, descontrol o desgaste de instituciones.

Así, incluso por ejemplo, Transparencia Internacional, aunque realiza muy diversos estudios como el Índice de Percepción de la Corrupción (IPC) 2010, legitima aquella concepción legalista, definiendo a la corrupción simplemente como el "abuso del servicio público para el beneficio particular o de terceros", cuando el combate a la corrupción no es sólo búsqueda o calificación de donde se cometen, al menos por percepción, más delitos. El combate a la corrupción y Corrupción como concepto es mucho más que eso: podemos concebir a la corrupción como el proceso de descomposición, desgaste, corrosión, envejecimiento o de disfuncionalidad de instituciones, lo cual permite como consecuencia, anomias individuales o colectivas. No sólo se trata de abatir el flagelo de la delincuencia, sino de CONTROLAR y abatir el flagelo del envejecimiento disfuncional natural de sistemas o instituciones de todo tipo: sindicales, familiares, religiosas, empresariales, gubernamentales, educativas, etc., lo cual da lugar a "fugas fáciles" del marco normativo y gubernativo.

Para re-funcionalizar o re-institucionalizar los deteriorados procesos operativos de los sistemas organizacionales de dichas instituciones, la ciudadanía, sociedad civil o el emergente "poder social" ha de desempeñar cierto rol protagónico que ha estado ignorando y dejando de cumplir con responsabilidad social.

"La lucha contra la corrupción: un pacto social.- En todo el mundo, contar con instituciones de control más sólidas, marcos legales estrictos y una reglamentación más rigurosa permitirá garantizar niveles más bajos de corrupción, así como una participación más significativa de todos los miembros de la sociedad, resultados más contundentes en materia de desarrollo y una mejor calidad de vida para las comunidades marginadas." ${ }^{33}$

\section{Hipótesis}

33.- Ibidem 
Hablar de "instituciones de control" más sólidas implica necesariamente, procesos incluidos de participación ciudadana que legitimen y contribuyan a "rejuvenecer" a las instituciones, que permitan darle credibilidad y recuperar la plenitud actualmente en declive.

Hablar así en los términos de Transparencia Internacional de "instituciones de control", lleva necesariamente a cuestionar, sobre todo desde la perspectiva de los Foros Mundiales pre comentados, la naturaleza social de las mismas. ¿Cuál sería entonces la función social de esas instituciones de control? -Simplemente asegurar que los mecanismos comunicativos entre todos los posibles actores sociales (gobiernos, ciudadanos, empresas, etc.), se realicen, confirmándolo o sancionándolo, a fin de asegurar la participación múltiple que genere efectos de satisfacción institucional generalizada.

A fin de visualizar lo anterior de manera empírica, dedicaremos ahora a corroborar estas últimas apreciaciones.

Participación de actores sociales (gobiernos, ciudadanos, empresas) en los SISTEMAS DE CONTROL GUBERNAMENTAL EN EUROPA Y OTROS PAÍSES, que asegure la satisfacción institucional generalizada.

En los países de la OCDE, sobre todo europeos, la función de regulación cubre cada vez más ámbitos como consecuencia de la complejidad de las sociedades, pero, por la misma complejidad, la producción de regulaciones requiere cada vez más la colaboración de organizaciones no gubernamentales.", valorándose de manera especial la relación entre la política de una sociedad y su dinámica administrativa $^{34}$, lo cual ha de mostrar a los gobiernos de los países latinoamericanos la necesaria apertura a escuchar (o a auditar) lo que la sociedad hace y desea a través de sus organizaciones, dejando de adivinar en las tinieblas del poder público esos elementos.

${ }^{34}$.Acuña, Carlos, (2007), Mirando la experiencia europea para comprender mejor la latinoamericana, p. 77 y 79 $\sim 45 \sim$ 
Por supuesto que para llegar a ello, es necesario primero transitar por un camino estratégico de fomento y facilitación de organización ciudadana que permita sin compromiso partidista alguno, generar como en Europa, aquellas políticas ciudadanas que se enlazan con la gestión pública.

"La experiencia europea enseña que... Una vez en marcha, los procesos muestran que las estrategias de modernización de la institucionalidad estatal deben redefinirse, adaptándose a la realidad, a veces radicalmente."

\section{Sistemas de control en América Latina}

En Colombia ${ }^{35}$ : existen diversos organismos asociados al Control social de la gestión pública, entre los que podríamos señalar, en el ámbito nacional, a la Defensoría del Pueblo y la Procuraduría General de la Nación. Existe además una Contraloría General de la Nación y una además en cada Departamento y de haber recursos una en cada municipio. A nivel de los municipios y Distritos están las Personerías. En el caso de Bogotá, existe también la Veeduría Distrital, que vela porque los empleados públicos cumplan cabalmente sus funciones.

La Procuraduría General de la Nación es el máximo organismo del Ministerio Público, representando a la sociedad colombiana, vigilando la conducta de los servidores públicos, advirtiéndole primero de manera preventiva cualquier hecho que pueda ser violatorio de las normas vigentes.

"A través de la Defensoría del Pueblo, el ciudadano se potencia, el ciudadano se fortalece. Se asume que si un ciudadano es la categoría más importante de una democracia, que si en él radica el origen político del poder democrático de las instituciones, que si el ciudadano es no solamente el origen sino el beneficiario directo de la función pública, el debe ser el

\footnotetext{
${ }^{35}$ Colombia junto con China, Grecia, Lesotho, Perú, Serbia y Tailandia ocupan el lugar número 78 de un total de 178 países analizados en la tabla del Índice de Percepción de la Corrupción 2010 de Transparency International. Habiendo obtenido 3.5 de Puntuación del IPC 2010. 
receptor final de la actuación de los distintos órganos en los que se manifiesta el poder público." ${ }^{\text {"36 }}$

Argentina $^{37}$ y Ecuador $^{38}$

Actualmente se encuentra en funcionamiento la Red Federal de Control Público, destinada a evaluar el desempeño de los programas sociales y mejorar la gestión de los mismos. La Red integra a las auditorías internas de todos los ministerios que ejecutan planes sociales y a la totalidad de los órganos de control externo de las provincias. A esta fecha se encuentra representada la totalidad de las jurisdicciones del país, a las que se han sumado varios tribunales de cuentas municipales.

El Comité de Auditoría Federal está integrado por todas las organizaciones adheridas, entre las que figura la Sindicatura General de la Nación (SIGEN) para el ejercicio de la Presidencia, la Auditoría General de la Ciudad de Buenos Aires para ejercer la Vicepresidencia y la Unidad de Auditoría Interna del Ministerio de Desarrollo Social como Secretaría ${ }^{39}$.

El 21de febrero de 2007 el Presidente de la República Ecuatoriana, Rafael Correa, anuncia la creación de la Secretaría Nacional Anticorrupción mediante Decreto Ejecutivo No. 122, con el objetivo de ejecutar la política gubernamental

\footnotetext{
${ }^{36}$ Manrique Reyes, Alfredo, (2007), Guía ciudadana para el control social de la gestión pública con enfoque de derechos humanos, en Revista Enlaces Jurídicos, julio, último acceso octubre 9, en: http://www.enlaces-juridicos.com.ar/web/496/, Buenos Aires, $64 \mathrm{p}$.

37 Argentina ocupa lugar número 105 de un total de 178 países analizados en la tabla del Índice de Percepción de la Corrupción 2010 de Transparency International. Habiendo obtenido 2.9 de Puntuación del IPC 2010.

${ }^{38}$ Ecuador junto con Bielorrusia, Líbano,Nicaragua Siria,Timor,Uganda ocupan el lugar número 127 de un total de 178 países analizados en la tabla del Índice de Percepción de la Corrupción 2010 de Transparency International. Habiendo obtenido 2.5 de Puntuación del IPC 2010.

${ }^{39}$ Entre sus objetivos se encuentran los siguientes: a) transferir los conocimientos y experiencia acumulada en el campo de la auditoría de programas sociales, en el contexto de la emergencia económica y social; b) compartir metodologías y programas de trabajo para abordar el análisis de las distintas modalidades que asumen los programas sociales en las provincias; c) conocer la normativa diversa que regula el control en las distintas jurisdicciones, a fin de compatibilizar la visión nacional con la provincial; d) intercambiar conclusiones extraídas de experiencias de campo propias y conjuntas, que sirvan para perfeccionar las acciones futuras; e) diseñar modelos de informes con formato básico homogéneo para todas las jurisdicciones, con la finalidad de hacer posible su compilación y posterior evaluación horizontal de los programas sociales nacionales; y f) desarrollar una estrategia conjunta de avance hacia auditorías más complejas previstas para el futuro.
} 
anticorrupción y elaborar estrategias para investigar, determinar y poner en conocimiento de las autoridades competentes, los actos de corrupción que incurrieren los funcionarios de la Administración Pública Central e Institucional, inclusive de las instituciones autónomas.

La Secretaría deberá coordinar estrechamente sus actividades con las entidades públicas y sociales cuyas funciones también están dirigidas a la lucha contra la corrupción, a saber: la Contraloría General del Estado, el Ministerio Público y la Comisión del Control Cívico de la Corrupción (CCCC). ${ }^{40}$

ESTUDIOS DE CASO Propuestas de Rediseño de ÓRGANOS DE CONTROL, ORGANIZACIÓN Y FUNCIONAMIENTO POR NIVEL DE GOBIERNO EN MÉXICO que asegure la satisfacción institucional e individual generalizada.

El 30 de septiembre de 2008 el presidente de México, Felipe Calderón, anunció el Programa Nacional de Rendición de Cuentas, Transparencia y Combate a la Corrupción $^{41}$, el cual tiene como propósito consolidar una política de Estado que permita fortalecer las buenas prácticas dentro de la función pública.

"Lo haremos con un enfoque de gestión más abierto, honesto, transparente y con una renovada vocación de rendición de cuentas, de modo que este programa también contribuirá al fortalecimiento de una cultura de apego a la legalidad, así como la construcción de una ética pública que sirva para establecer valores y principios que guíen y orienten la actuación de servidores públicos y de la sociedad con las instituciones", aseveró.Tras afirmar que la corrupción daña la confianza, el mandatario mexicano

\footnotetext{
${ }^{40}$ Entre los objetivos que debe cumplir están el de obtener información a través de los diferentes organismos de la Fuerza Pública; analizar la información recopilada y estudiar la procedencia jurídica de las acciones a emprender; elevar el informe final de investigaciones a las autoridades competentes y solicitar se inicien las acciones pertinentes en contra de los presuntos autores de los actos de corrupción; dar seguimiento a los procesos iniciados; diseñar, monitorear y evaluar la ejecución de las políticas y estrategias para la lucha contra la corrupción. Se establece que las atribuciones del Secretario Nacional son las de sugerir la política anticorrupción al Presidente de la República y elaborar estrategias para investigar y denunciar los actos de corrupción, aprobar planes y proyectos presentados por las diferentes unidades administrativas, de expedir las resoluciones dentro del ámbito de competencia y informar a la comunidad sobre la gestión realizada. (ver http://www.presidencia.gov.ec/noticias.asp?noid=8592).

http://www.programaanticorrupcion.gob.mx/prctcc 2008-2012.pdf
} 
refrendó el compromiso de su Gobierno con la cero tolerancia a la corrupción.

"Esto es lo que yo exijo a los servidores públicos y es lo que les ofrezco a los mexicanos", declaró. Destacó además que hoy en día las sociedades demandan con mayor fuerza gobiernos más abiertos al escrutinio y a la evaluación e indicó que para llegar a este objetivo es necesario transitar de una cultura de la corrupción a una cultura de legalidad, transparencia y honestidad.

"Se necesita que los servidores públicos y los ciudadanos, no sólo asuman la responsabilidad de aplicar y de hacer cumplir la ley, sino también actúen para prevenir y erradicar la corrupción en sus distintas modalidades", aseguró.

Afortunadamente en México, los procesos de creación de información gubernamental han pasado por fases de maduración tal, que permiten aseverar que "aunque gubernamental ${ }^{42}$ ", el ciudadano común puede acceder a datos, estadísticas, información, sea a través del Instituto Nacional de Estadísticas, Geografía e Informática (INEGI), o de la institución gubernamental que la genera, ello por virtud de la etapa de acceso transparente a la información que jurídicamente permite hacerla accesible. En los órganos de control precitados se puede extraer el común denominador al que hacemos referencia y confirma nuestra hipótesis: "“'Instituciones de control” más sólidas implica necesariamente, procesos incluidos de participación ciudadana que legitimen y contribuyan a "rejuvenecer" a las instituciones, que permitan darle credibilidad y recuperar la plenitud actualmente en declive.

A continuación presentamos la estructura actual y tres propuestas de rediseño institucional que asegure la satisfacción institucional generalizada y por ende la satisfacción del usuario.

\footnotetext{
${ }^{42}$ La expresión "aunque gubernamental", obedece al principio general de la fuente: se genera de donde sale. Si quien ejerce el poder de control y de decisión se ve precisado a proporcionar una información, esta se maquilla de acuerdo a los intereses de la fuente, sobre todo, en las estadísticas gubernamentales.
} 
Estudio de Caso: Propuesta de Rediseño de institución de Nivel Federal

En la Administración Pública Federal y particularmente en la esfera del Poder Ejecutivo, "opera" un Sistema de Control y Evaluación en el marco del Comité de Planeación para el Desarrollo del Estado de Sonora (COPLADES) el cual en calidad de Sub-Comité Especial, está coordinado por el Secretario de la Función Pública (SFP), Secretaría que a la vez opera diversos sistemas y programas enmarcados en la estructura orgánica ${ }^{43}$ siguiente:

${ }^{43}$ Es de advertir, que, puede resultar nocivo presentar a una institución gubernamental a partir de su estructura, por diversas razones entre las que destacan su enfoque orientado a los límites de autoridad responsabilidad en una visión vertical (ni transversal ni inter-sectorial), lo cual prohíja defectos de visión que se traducen, como veremos, en obvias duplicidades de órganos, de funciones y de presupuestos que regularmente no alcanzan a apreciarse, sobre todo si asociamos su funcionamiento a un orden sistémico que permita encuentros con incongruencias funcionales 




Fuente:http://www.funcionpublica.gob.mx/pt/obligaciones transparencia art 7/sfp/ estructura n/O/ORG0 1.htm Organigrama vigente desde diciembre de 2006 
En 2001, con la Carta Iberoamericana de la Función Pública suscrita por mandatarios de todos los países, se generó en forma refleja en México para 2003 la Secretaría de la Función Pública (SFP), la cual aunque por iniciativa presidencial en septiembre de 2009 se pretendió su desaparición, contó a partir de 2003 con la Ley correspondiente y el Reglamento a dicha Ley en 2004, soportando el primer documento jurídico breves modificaciones en 2006, y permitiendo a esa SFP disponer de una estructura orgánica enorme y con evidentes disfuncionalidades estructurales.

En otras palabras: Se debe tomar con cautela y reservas la estructura antes presentada, la cual si analizamos en términos de comprensión y refuncionalizar(no de re-estructurar), podríamos presentarla en los términos siguientes:

Si bien la función de una contraloría (como órgano de control de "la administración pública") es centralmente pretender ser garante sobre todo de legitimidad de esa función pública que se desarrolla con recursos, procesos e instituciones públicas... ¿Por qué no promover y facilitar la organización ciudadana para que sea ella y no particulares o empleados de gobierno quienes la controlen y evalúen? El estratosférico presupuesto ${ }^{44}$ que maneja la SFP y múltiples organismos réplica de ella en cada dependencia y entidad, muestra el despilfarro e incongruencia de la administración pública con esta función realizada desde la esfera del poder público: para el desarrollo de 8 programas existen 29 órganos con nivel de Dirección General o equivalente, lo cual contraviene el principio de "unidad de dirección", tenemos 21 órganos que o no programan sus responsabilidades funcionales, o realizan funciones que no se justifica(corrupción), lo cual sin entrar en mayores profundidades de análisis es muestra evidente de que la SFP se ha constituido en botín político de los partidos donde colocan a incondicionales empleados que arriban a esa estructura a servirse antes que a servir.

\footnotetext{
${ }^{44}$ 1,346,104,529 Fuente: Diario Oficial de la Federación Cuarta Sección Secretaría de Hacienda. Presupuesto de Egresos de la Federación para el Ejercicio Fiscal 2011pp 54
} 
Propuesta de re-funcionalización promover que la ciudadanía organizada y actuando mediante contratos de concertación (no de concesión, que sería ceder al sector privado la función), de manera especializada en células de "expertos" sin fines de lucro, realizar funciones de control de sistemas, no simples y costosas auditorías ni veedurías ciudadanas gratuitas, sino realizado desde la ciudadanía que evite el pernicioso ciclo histórico del poder de constituirse en juez y parte. A manera de fundamentar lo expuesto y de facilitar el análisis, se presentan algunos elementos de la SFP que se han rescatado de su página web:

Misión.- Consolidar un Gobierno honesto, eficiente y transparente. Visión 2020.La ciudadanía participa y confía en la Función Pública.

Como hemos señalado un poco antes, la misión de cualquier organismo que pretendiera asegurar que se está haciendo lo correcto (controlar verificando), y que lo que se hizo generó el cumplimiento de una propuesta o promesa y con ello un cambio ciudadano esperado (evaluar fiscalizando).

Acciones gubernamentales prioritarias.- Promover la cultura de la legalidad y el aprecio por la rendición de cuentas. Ampliar la cobertura, impacto y efecto preventivo de la fiscalización a la gestión pública. Inhibir y sancionar las prácticas corruptas. Articular estructuras profesionales, eficientes y eficaces del gobierno. Mejorar la regulación, la gestión y los procesos de la APF. Optimizar el uso y aprovechamiento de los inmuebles federales.

Programas: Lenguaje ciudadano ${ }^{45}$, Anual de Disposición Final de Bienes, De Blindaje Electoral 2009, Mejora de la Gestión, Nacional de Rendición de Cuentas, Transparencia y Combate a la Corrupción 2008-2012, Usuario Simulado, Manuales de Aplicación General,Contador de Normas Eliminadas Consolidadas,

\footnotetext{
${ }^{45}$ Se refiere a un programa intencionado para promover el empleo de un lenguaje claro, simple, llano y directo. "Lenguaje ciudadano" se lanzó desde el 5 de octubre de 2004 como parte de los trabajos de mejora regulatoria dentro de la agenda de buen gobierno. Está a cargo de la DG de Simplificación regulatoria. Surge de las buenas prácticas de comunicación usadas en los gobiernos de los países como Suecia, Australia, Reino Unido, Canadá y Estados Unidos denominadas "Plain Lenguaje" o "Lenguaje llano" en España.
} 
Como puede observarse, para sólo nueve (9) programas existen veintinueve unidades administrativas (29) dentro de la SFP ${ }^{46}$, haciéndose evidente que existen pocos programas para iiimuchísimos puestos directivos!!!

Asimismo, en el marco de la realización de actividades de control, pero ahora en el seno del Congreso de la Unión, con la aprobación de la Ley de Fiscalización y Rendición de Cuentas (Que derogó en mayo de 2009 la Ley de la Auditoría Superior de la Federación) significó un cambio trascendente en la organización de la Auditoría Superior de la Federación (ASF). Esta Ley presenta entre otros elementos interesantes, un nuevo capítulo que crea la figura de la Contraloría Social, que permitirá a los ciudadanos y organizaciones de la sociedad civil presentar propuestas de auditoría y someterlas a consideración del auditor superior.

Al frente de la ASF está el Auditor Superior de la Federación, quien es designado para un periodo de ocho años, por el voto de las dos terceras partes de los miembros presentes de la Cámara de Diputados, conforme a lo previsto por el párrafo tercero del artículo 79 de la Constitución Política de los Estados Unidos Mexicanos.El Auditor Superior está apoyado por tres Auditores Especiales: de Cumplimiento Financiero, de Desempeño y de Planeación e Información. Así como por los titulares de las unidades de Asuntos Jurídicos y General de Administración. También forman parte de este entramado institucional los coordinadores de Control y Auditoría Interna (Unidad de Evaluación y Control de la ASF) y de Relaciones Institucionales.

Por otro lado, el 10 de septiembre de 2008 se publicó en el Diario Oficial de la Federación el Programa Especial de Mejora de la Gestión de la Administración Pública Federal, 2008-2012, el cual tiene entre sus objetivos mejorar la calidad de los bienes y servicios e incrementar la efectividad de las instituciones, siendo la

\footnotetext{
46 Unidades administrativas entre las cuales se encuentra la misma Secretaría, tres sub secretarías, diez direcciones generales, trece unidades, una coordinación, la contraloría interna, sin contar con Instituto de Administración y Avalúos de Bienes Nacionales; Delegados, Subdelegados y Comisarios Públicos; Titulares de Órganos Internos de Control y los de sus áreas de Auditoría, de Quejas y de Responsabilidades, y Supervisores Regionales. $\sim 54 \sim$
} 
participación ciudadana uno de los cinco ejes que lo conforman y facilitando su actuación a través del sistema de atención y participación ciudadana elaborado para ese mismo efecto ${ }^{47}$. Sin embargo, dicho sistema está diseñado para operarse desde la Secretaría y no desde organizaciones ciudadanas sólo a través de un cuestionario trimestral de evaluación del servicio con un solo indicador de satisfacción. ${ }^{48}$

A pesar de ello, el propio Secretario de la Función Pública ha reconocido que trámites, estructuras y normas del Gobierno Federal provocan dificultades en la relación con los ciudadanos y los usuarios ${ }^{49}$

47.- Manual disponible en http://www.funcionpublica.gob.mx/images/doctos/PROGRAMAS/pmg/manual de operacion pmg 2011.pdf 48.- Ver:

http://portal.funcionpublica.gob.mx:8080/wb3/work/sites/SFP/resources/LocalContent/1623/2/sistema atencion ciudadana octubre 2008.pdf p. 25

.- Vega casillas, Salvador, (2008), Discurso, op cit., p. 2 


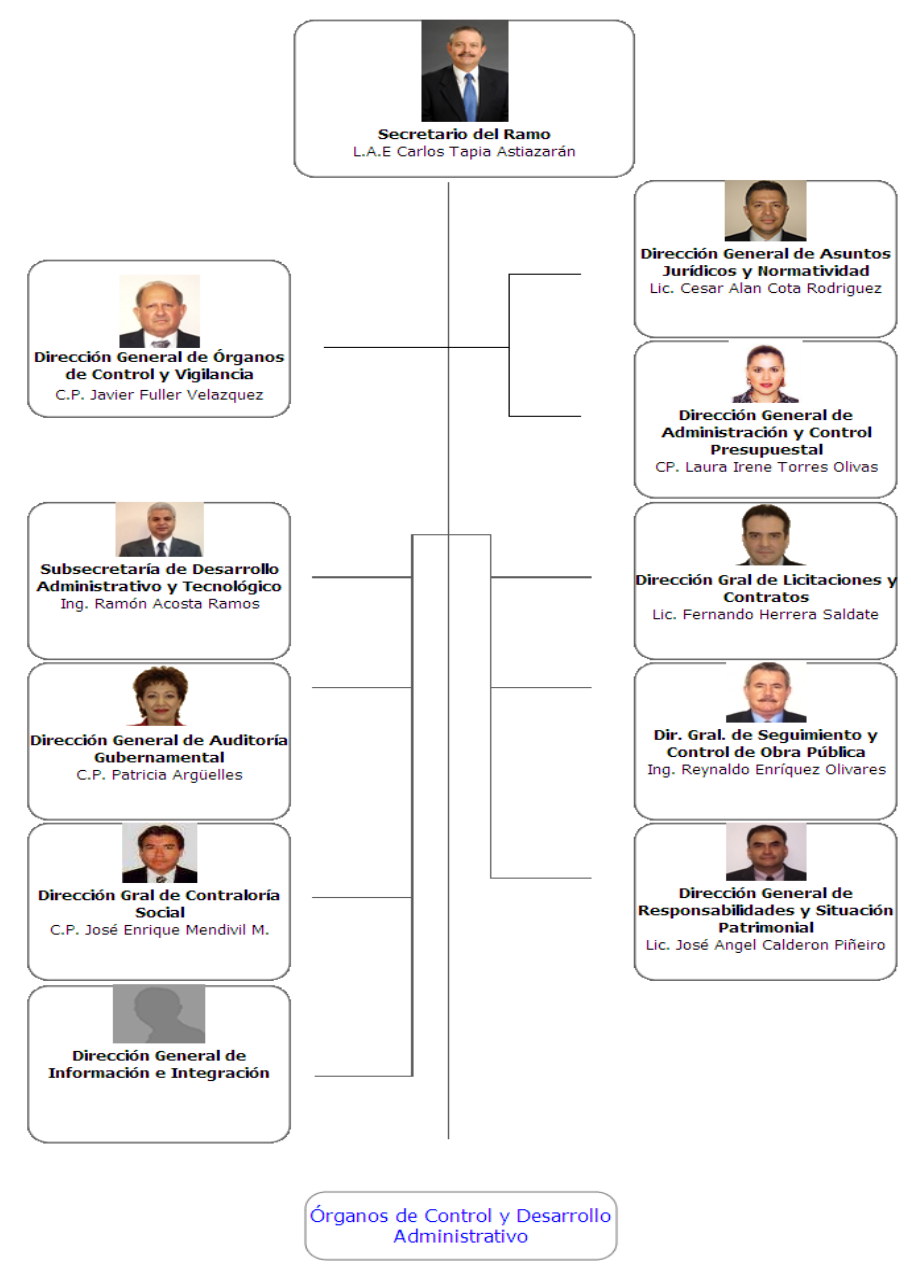

Estudio de Caso: Propuesta de Rediseño de institución de Nivel Estatal.

Para el caso del Estado de Sonora, en el poder Ejecutivo de Gobierno el sistema de control, al igual que en el nivel federal, se encuentra coordinado sectorialmente pero por la Secretaría de la Contraloría General (SCG) por lo que resulta válido el cuestionamiento realizado a su homóloga federal y la propuesta de participación ciudadana en las funciones de control de sistemas. El estratosférico 
presupuesto $^{50}$ que maneja la SCG y múltiples organismos réplica de ella en cada dependencia y entidad, muestra el despilfarro e incongruencia de la administración pública con esta función realizada desde la esfera del poder público.

En esta misma amplitud territorial, en el Congreso del Estado, se contaba con lo que fue la Contaduría Mayor de Hacienda, la cual fue suplida por el Instituto Superior de Auditoría y Fiscalización (ISAF), regido por la Ley 169 de Fiscalización Superior para el Estado de Sonora, que dependiente de la Comisión de Vigilancia del mismo Congreso del Estado, se constituye como el órgano de Fiscalización Superior del $\mathrm{H}$. Congreso del Estado de Sonora y que tiene por objeto fiscalizar los recursos públicos en forma imparcial y transparente, conforme a los diferentes ordenamientos legales que rigen su funcionamiento, promoviendo la transparencia y la rendición de cuentas por parte de cualquier ente público o privado que maneje, custodie o aplique recursos públicos del Estado o municipios. Por este medio se genera información veraz y oportuna sobre el resultado de la revisión del origen y aplicación de los recursos públicos del Estado y municipios, así como toda aquella información relevante en materia de auditoría gubernamental de interés para la sociedad sonorense. Es de comentar que la Ley que rige al Instituto, presentada como iniciativa por la fracción panista en 2007, durante la gestión de un gobernador prísta, ha quedado demasiado limitada o trunca, ya que deja de promover la organización ciudadana y su participación en esas actividades de fiscalización. Sin embargo la organización de los contribuyentes sonorenses se ha plasmado en la ONG Sonora Ciudadana $A C, 1 a^{51}$ que en su página web se describe como

\footnotetext{
${ }^{50}$ Secretaría de la Contraloría General 86,633 96,959 10,326

${ }^{51}$ http://www.sonoraciudadana.org.mx/images/PDF/mls-ultima-publicacion.pdf 
"Centro de Investigación para la Democracia y el Desarrollo, trabaja a favor de la ciudadanía con un alto compromiso social. No vende asesorías ni el fruto de sus investigaciones. Toda capacitación técnica, asesorías de fortalecimiento institucional y de capacitación hacia los funcionarios públicos u organismos no gubernamentales se hace gratuitamente a favor de la misma ciudadanía. Contar con funcionarios públicos con perspectiva de género y derechos humanos, es una inversión a favor de la población."

\section{Estudio de Caso: Propuesta de Rediseño de institución de Nivel Municipal, el caso de la Contraloría de Hermosillo}

\section{Antecedentes $^{52}$}

El control interno en el H. Ayuntamiento de Hermosillo, hasta finales de 1985, comprendía exclusivamente el aspecto financiero, función que estaba bajo la responsabilidad de Tesorería Municipal, misma que realizaba a través de su unidad de auditoría interna, así como proporcionar la información requerida por los despachos de auditoría externa contratados por el $\mathrm{H}$. Ayuntamiento. Es en septiembre del mencionado año cuando se creó un Órgano de Control Interno, que además de regular el cumplimiento del aspecto financiero de las dependencias y entidades de la Administración Pública Municipal, realizaba las funciones relativas a la planeación, a este órgano se le denominó Contraloría, el cual jerárquica y funcionalmente dependía de Sindicatura Municipal.

Dentrode sus actividades están la creación y publicación de la guía ciudadana presupuestaria y laaplicación del Indicador de Cumplimiento de la Información de Oficio y Semáforo de la Transparencia, entre otras.

EI ICIO es un ejercicio de investigación aplicada que sintetiza el seguimiento a 12 sujetos obligados por la Ley de Acceso a la Información Pública del Estado de Sonora (LAIPES), en cuanto al cumplimiento de publicación de la información de oficio estipulada en los artículos 14, 17 y 36 de la misma ley.

Para lograr el objetivo general de esta investigación, se diseñó un sencillo indicador de cumplimiento de la información de oficio (ICIO), que evalúa el porcentaje de cumplimiento de 18 variables.

En este sentido, el cálculo del ICIO se constituye como la única información disponible en el Estado en esta materia, ya que los encargados de vigilar y hacer cumplir la transparencia en Sonora no han realizado acciones al respecto.

52 Antecedentes tomados del manual del Organización del Órgano de control y evaluación del Ayuntamiento de Hermosillo, sito en www.hermosillo.gob.mx 
Posteriormente, en 1990, Contraloría se eleva al rango de Dirección General y se le denominó Dirección General de la Contraloría Interna, la cual contaba con las siguientes unidades administrativas: Dirección General, Subdirección de Auditoría Gubernamental y Subdirección de Organización y Métodos.

En la administración municipal correspondiente al período 1991-1994 con el propósito de lograr una mejor productividad y eficiencia en la Dirección General de la Contraloría Interna, se efectúan cambios en su estructura organizacional, integrándose con las siguientes unidades administrativas: Dirección General, Dirección Jurídica, Dirección de Auditoría Gubernamental, Dirección de Control de Obras y la Dirección de Organización y Métodos. A partir de la administración 1994-1997, la Dirección General de la Contraloría Interna, cambia de denominación, quedando como Contraloría Municipal, debido a que es el nombre que la Ley Orgánica de la Administración Municipal vigente en ese tiempo le otorgó. En la administración 1997-2000 los cambios más significativos fueron, primero, la fusión de la Subdirección de Control de Obra a la Dirección de Auditoría Gubernamental, así como la modificación del nombre de la Dirección de Organización y Métodos a Dirección de Organización, Procesos y Sistemas.

En la administración 2000-2003 la Subdirección de Control de Obra se separa de la Dirección de Auditoría Gubernamental, quedando la primera nuevamente como Dirección, se modifica el nombre de la Dirección de Organización, Procesos y Sistemas, quedando como Subdirección de Auditoría Administrativa y, por último, la Dirección de Asuntos Internos, la cual dependía de la Secretaría del H. Ayuntamiento, pasa a ser una unidad administrativa de Contraloría Municipal. A partir de que entra en vigor la Ley de Gobierno y Administración Municipal en el 2001, se crea el Órgano de Control y Evaluación Gubernamental, siendo el Contralor Municipal el encargado de las funciones establecidas en el Artículo 96 de la Ley en mención, como Titular de la dependencia. 
En la administración 2003-2006 la estructura orgánica no se modifica, con respecto a la administración próxima pasada, contaba con una Contraloría Municipal u Órgano de Control y Evaluación Gubernamental, Dirección de Auditoría Gubernamental, Dirección de Control de Obra Pública, Dirección de Asuntos Internos y Dirección de Determinación de Responsabilidad Administrativa, así como con un Departamento Administrativo.

En la administración 2006-2009 se desincorpora la Subdirección de Auditoría

Administrativa de la Dirección de Auditoría Gubernamental, quedando en la estructura orgánica con dependencia directa del Despacho del Contralor y se modifica su nombre a Subdirección de Evaluación al Desempeño, asimismo, se crea la Coordinación de Vinculación Institucional, también ésta con dependencia Directa del Titular de la Dependencia, por otra parte, el Departamento Administrativo cambia su nombre a Coordinación Administrativa. La estructura actual de Contraloría Municipal es la siguiente: 


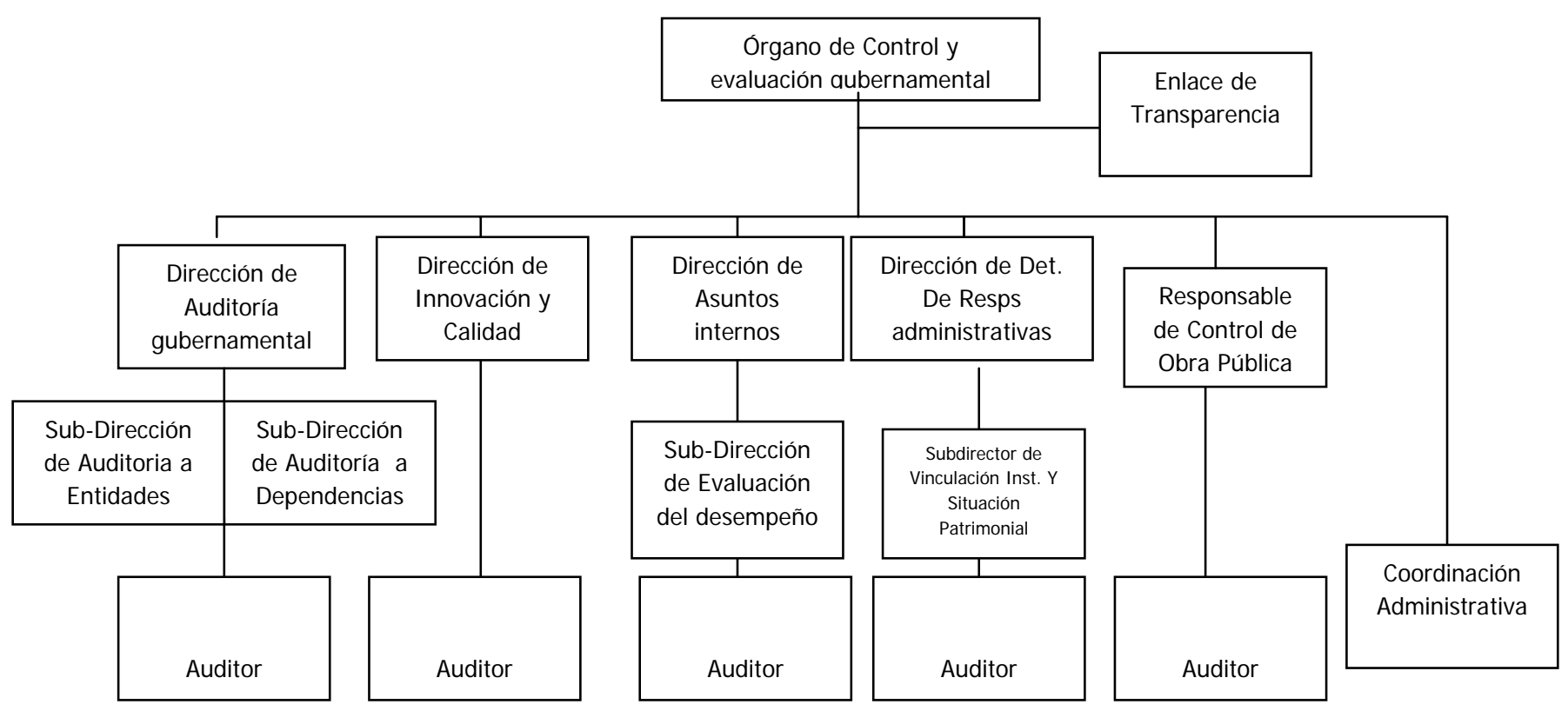

Fuente: Elaboración Propia con datos tomados del directorio de la contraloría del ayuntamiento de Hermosillo, Sonora. http://www.hermosillo.gob.mx/entidades/?id=10

ANÁLISIS.- El enorme crecimiento y el caprichoso cambio constante de estructuras funcionales de este órgano de control interno del Ayuntamiento de Hermosillo deja entrever, junto a su presupuesto anual de operación, que para el 2011 asciende a 1,770,430,653.11) ${ }^{53}$, cinco elementos críticos:

- La exposición de este órgano a las eventualidades políticas, cambios de criterios por partido y por director general en su organización y funcionamiento, lo cual pone a la deriva su curso de navegación

\footnotetext{
${ }^{53}$ Dato tomado mes de marzo de 2011del link de transparencia y acceso a la información pública en www.hermosillo.org.mx
} 
caprichoso, cuando debiera ser orientado primero a consolidarse y luego a impactar, desde una cierta legitimidad ciudadana en los servicios públicos.

- Muestra un desconocimiento evidente de la teoría administrativa y los benéficos efectos que ésta pudiera generar sobre procesos de control, al confundir o al menos desplazar de su relevancia al órgano que existía de "Organización, procesos y sistemas", cambiándole fácil y simplemente el nombre a Auditoría administrativa, como si las funciones que les corresponden son de la misma naturaleza, o relegando de importancia la función que implicaba la primer denominación.

- No se cuenta técnicamente con organigrama en su portal de internet.

- Un presupuesto de cantidades considerables

\section{Control Social: Contralorías Sociales o ciudadanas}

Una clara tendencia que se puede percibir en torno al logro de efectos de satisfacción ciudadana y de legitimación de las acciones gubernamentales lo es sin lugar a dudas el reto de ciudadanizar las contralorías que actualmente operan en casi todas las esferas de los poderes públicos, al menos en México.

De acuerdo a resultados promocionales realizados desde la década de 1990 a efectos de formar contralores sociales, “...es muy poco el número de personas que conoce y menor aún el que participa en dichos mecanismos. Estas formas de participación no son conocidas por la mayoría de la población ni por los propios usuarios." ${ }^{154}$ Además de que han sido bastas las actividades y recursos promocionales destinados a operar mecanismos de Contraloría Ciudadana (CC) en México, pero la fuente de legitimidad de las $\mathrm{CC}$ radica en la efectividad que generen en tanto sistema de contrapeso ciudadano ante los gobiernos, presentándose el riesgo de ser una forma de participación decorativa, no deliberativa ${ }^{55}$ y más aun, de dejar de tener atribuciones resolutorias.

La participación ciudadana en acciones de contraloría social es todo un reto de empoderamiento ciudadano, ya que ante "...la polivalencia y relativa dificultad de

\footnotetext{
${ }^{54}$ Hevia de la Jara, Felipe, (2006), La contraloría social mexicana: participación ciudadana para la rendición de cuentas Programa Interinstitucional de Investigación-Acción sobre Democracia, Sociedad Civil y Derechos Humanos, Instituto de Investigaciones, Histórico-Sociales, Universidad Veracruzana, México.pp.49

${ }^{55}$ Hevia de la Jara Op.cit pp52
} 
definir en términos concretos y operativos lo que es y no es contraloría social", aquí hemos ya precisado que las $\mathrm{CC}$ son espacios participativos (y no sólo gubernamentales decorativos), que permite el desarrollo de capacidades y de efectos de satisfacción ciudadana desde lo gubernamental, habiéndose adoptado ideológicamente la opción teórica que nos plantea Amartya Sen,, de fortalecer las capacidades ciudadanas para el desarrollo humano y social, lo cual devela de entrada, la necesidad de conceder a la misma ciudadanía no sólo espacios para las fotos, en su caso las denuncias y las cifras, sino para ejercer su poder de resolver de manera autónoma no sólo condiciones detectadas de sesgos o de anomia administrativa, sino orientador de sanciones, de proponer mecanismos legislativos que impidan la impunidad en todos los órdenes de la vida gubernamental, así como acrecentar los efectos de satisfacción de la acción pública.

En otras palabras: las CC son, además de un espacio ciudadano, un sistema complejo de actuación autónoma orientado a diversos efectos, entre los cuales se destacan:

- La vigilancia o veeduría clásica sobre cumplimiento de normas

- La denuncia y direccionar demandas hacia las procuradurías de justicia;

- La detección de deficiencias de procesos y propuestas de rediseños

- La comunicación ciudadana de masas sobre sus resultados

- El ejercicio de recursos autónomos para la operación del sistema

- El logro de una gradual y legítima efectividad desde el gobierno

Actualmente, como ya lo hemos señalado, para estimular la CC el Gobierno Federal mexicano ha diseñado estrategias como la edición accesible del Manual de Monitoreo Ciudadano, sin embargo, no se alcanza con ese monitoreo a incidir de manera resolutoria en la mejora de la gestión gubernamental; ello sigue estando de la mano de la voluntad política de los dirigentes en turno de cada una de las instituciones. 


\section{Conclusiones}

Tres razones para utilizar la metodología de sistemas en la construcción de instrumentos y mecanismos jurídicos locales (control socio gubernamental)que garanticen transparencia y rendición de cuentas"

Permite su enfoque deducir o inducir el estudio de un caso.- El abordaje de un caso de proceso institucional se puede repensar con casos similares en situaciones diferentes y con ello dar luz sobre posibilidades o arreglos creativos hasta ese momento inimaginables; igual sucede de manera inversa: casos diferentes en el mismo contexto, todo lo cual generalmente es visto sin relación con el todo, sin pensar en deducir o inducir arreglos pertinentes y plausibles que de otra manera no fuera posible concebirlos.

Permite orientar el diseño de sistemas.- Ello según su proceso y no según su finalidad, lo cual brinda otras alternativas de reordenamiento. Se concibe cada caso de manera compleja para deconstruirlo (desbaratarlo en partes o sub procesos para su análisis) y proceder a su reconstrucción en redes coherentes de participación.

Brinda la posibilidad de analizar articuladamente las condiciones cuantitativas ancladas necesariamente a las cualitativas.

\section{BIBLIOGRAFÍA}

Acuña, Carlos, (2007), Mirando la experiencia europea para comprender mejor la latinoamericana: notas comparadas sobre las políticas de modernización estatal, pp. 75-92, en Scelza Cavalcanti, Bianor, (2007)

Adam Adam, Alfredo y Becerril Lozada, Guillermo, (1988) La fiscalización en México, Ediciones UNAM 
Albomaz, Mario y Ernesto Fernández P., (1997), Indicadores en ciencia y tecnología: reencuentro de la política con la gestión, en Solleiro, José Luis y Rodolfo Faloh "Innovación, competitividad y desarrollo sustentante", Edic. CITUNAM-ALTEC, memorias del VII seminario Internacional de gestión tecnológica, 3V, T2, 26-30 octubre, La Habana,

Berger, P. y Luckman T., (1995), La Construcción Social de la Realidad. La Sociedad como realidad objetiva, Amorrortu.

Bobadilla, Indhira, (2009), El Locus del control, Revista Apolorama, No. 6, enero febrero, México, http://www.revistaapolorama.com

Bozeman, Barry, (1998), La Gestión Pública su situación actual, FCE, México

Cabrero Mendoza, Enrique, (1998), Gestión Pública, la administración pública de siempre bajo un nuevo disfraz?, en Barry Bozeman

Cabrero Mendoza, Enrique, (2005), Acción pública y desarrollo local, Editorial Fondo de Cultura Económica, México

Calderón Hernández Gregorio y Castaño Duque Germán Albeiro, (2005), Investigación en Administración en América Latina: Evolución y resultados, ediciones Universidad Nacional de Colombia, memorias del Congreso Iberoamericano de Investigación en Administración, mayo 11-13, Manizales

Consejo Metropolitano de Quito, (2000), Ordenanza De Concejo "de sus Comisiones y de la Participación de la Comunidad", Libro Primero del Código Municipal, Capítulo II del Título I, Quito, Ecuador.

Consejo de Bogotá, (2002), Acuerdo 067 por el cual se dictan normas que garanticen la participación y veedurías ciudadanas en la gestión pública Distrital, Exposición de motivos, Colombia 
Consejo de la Juventud de España, (2000), Guía didáctica de educación para la participación, Fundación EDE, http://www.cje.org, Madrid

Diammond, Stanley, (1971), El rol del Derecho y la Costumbre, en Robert P. Wolf $(E d)$, "The rule of the Law", NY

Díaz Velázquez, Eduardo, (2009), El estudio sociopolítico de la ciudadanía: fundamentos teóricos, en Intersticios, Revista sociológica de pensamiento crítico, Vol. 3, No. 1, Universidad Complutense de Madrid

Fernández Ruiz Jorge, Salgado Ledesma, Eréndira.(2009),Derecho Administrativo del Estado de Sinaloa, Ed. Porrúa México

Fernández Santillán, José, (2001), Súbditos o ciudadanos, sociedad civil y derechos ciudadanos, en Revista Letras Libres, No. 26, año III, febrero, México

Foucault, Michel, (2000), Defender la sociedad, curso en el College de France, 1975-1976, traducido al castellano por Horacio Pons, Fondo de Cultura Económica, Argentina

Siglo XXI,

Giddens, Anthony, (1999), Un mundo desbocado, Taurus

, (1999), La tercera vía: la renovación de la socialdemocracia,

Santillana-Taurus

, (2000), Teoría de la estructuración, Editorial , (2006), Teoría social hoy, Alianza Editorial, Madrid

González Casanova, Pablo, (1987), La falacia de la investigación en ciencias sociales, Edit. Océano, México, 
Guerra, Gabriel, (2009), A un mes del golpe en Honduras, entrevistado por Carmen Aristegui, CNN en Español, julio 28

Guerrero, Omar (1989), El Estado y la Administración Pública en México, ediciones INAP, versión electrónica en: www.bibliojuridica.org/libros

Gutiérrez, María Elsa, (2002), Panorama actual de la teoría de representaciones sociales: tendencias y debates, en memorias del III Congreso Iberoamericano de Psicología, tendencias de la Psicología del tercer milenio, 21-27 de julio, Bogotá.

Hernández Pedro A., (2005), Propuestas de Participación Ciudadana en la Gestión Municipal, Sistematización: Fundación Solidaridad, República Dominicana, PW www.solidaridad.org.do

Hathayug, (2009), El Derecho como forma de control social, 3 p. http://www.autorneto.com/Literatura/Ensayos/El-Derecho-como-forma-de-controlsocial.490591

Hevia de la Jara, Felipe, (2006), La contraloría social mexicana: participación ciudadana para la rendición de cuentas, Programa Interinstitucional de Investigación-Acción sobre Howe, David y Enrique E Raya Lozano (1999), Dando sentido a la práctica: Una introducción a la teoría del trabajo social, Tít. original: An introduction to social work theory: making sense to practice Ediciones Maristán

López Ochoa, Marco Antonio, (2009), Los derechos Humanos, en Revista Buena Salud, año 11, No. 106, enero, México, pp. 28-29

Luhmann, Niklas, (1997), Organización y decisión. Autopoiesis, acción y entendimiento comunicativo, Edit. Anthropos, Barcelona

(1998), Complejidad y modernidad de la unidad a la diferencia, Edit Trotta, España

-- (1998), Teoría de la sociedad, Editorial Triana-UI, México 
--- (2005), El derecho de la sociedad, Edit. Herder (2007), La sociedad de la sociedad, Edit. Herder

Manrique Reyes, Alfredo, (2007), Guía ciudadana para el control social de la gestión pública con enfoque de derechos humanos, en Revista Enlaces Jurídicos, julio, último acceso octubre 9, en: http://www.enlaces-juridicos.com.ar/web/496/, Buenos Aires

McCaughan Nano y Palmer, Barry, (2005), El pensador sistémico, Panorama, México

Milward, H. Brinton, PROVAN, Keith G. y ELSE, Bárbara A., (1998), Qué es el "Estado Hueco"?, en Bozeman

Monteverde Maldonado, Eduardo, (2009), Nuestra sociedad está enferma, en Revista Buena Salud, Año 11, No. 106, enero, México

Morales Zamorano, Miguel Arturo, González Beltrones Adria V., Banda Castro Ana Lilia, y Valenzuela Miranda Gpe. Aleyda, (2006), Participación ciudadana y reinstitucionalización de la gestión pública en territorios municipales", comunicado presentado durante el VIII Congreso Iberoamericano de Municipalistas, noviembre 11-16, Guayaquil, Ecuador

Morales Zamorano, Miguel Arturo, Banda Castro Ana Lilia, González Beltrones Adria V., Valenzuela Miranda Gpe. Aleyda,Avendaño Enciso Alipia (2010) Sistemas de Control Socio Gubernamental México Ed SEP PIFI UNISON

Moreno Abril, Karla, (2006), Advierten de "retrocesos" en nueva Ley de Transparencia, en diario Cambio Sonora, sábado 1 de julio, Secc. Estatal, en PW: www.cambiosonora.com

Moscovici, S. (1979), Psicoanálisis su imagen y su público, Paidos, Buenos Aires (1993), Psicología Social, T.II. Paidós, Barcelona 